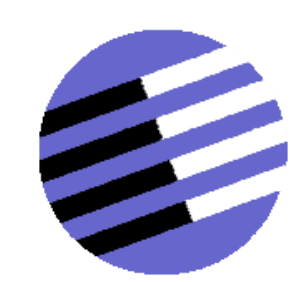

GOVERNANCE AND THE EFFICIENCY

OF ECONOMIC SYSTEMS

GESY

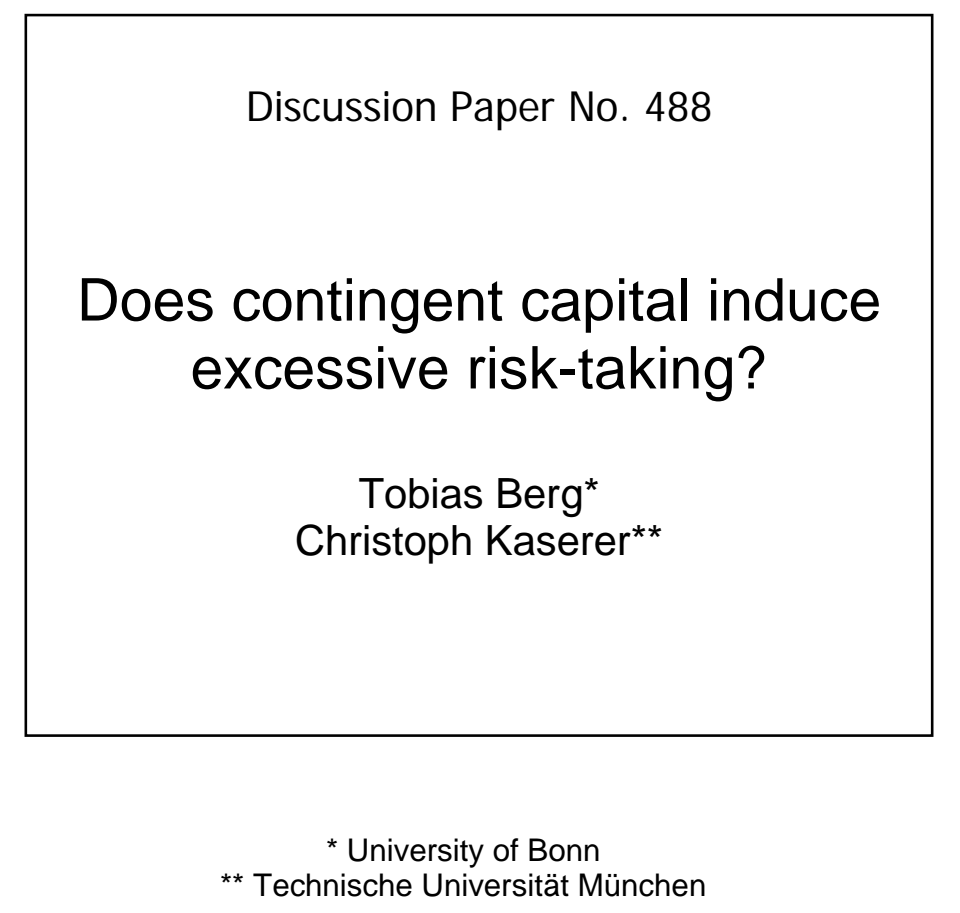

Financial support from the Deutsche Forschungsgemeinschaft through SFB/TR 15 is gratefully acknowledged.

Sonderforschungsbereich/Transregio $15 \cdot$ www.sfbtr15.de

Universität Mannheim · Freie Universität Berlin · Humboldt-Universität zu Berlin · Ludwig-Maximilians-Universität München Rheinische Friedrich-Wilhelms-Universität Bonn · Zentrum für Europäische Wirtschaftsforschung Mannheim 


\title{
Does contingent capital induce excessive risk-taking?*
}

\author{
Tobias Berg ${ }^{\dagger}$ \\ University of Bonn \\ Adenauerallee 24-42 \\ 53113 Bonn \\ Email: tobias.berg@uni-bonn.de \\ Tel: +49228736103. \\ Christoph Kaserer \\ Technische Universität München \\ Arcisstr. 21 \\ 80333 München \\ Email: christoph.kaserer@wi.tum.de \\ Tel: +49 8928925489
}

\begin{abstract}
In this paper, we analyze the effect of the conversion price of $\mathrm{CoCo}$ bonds on equity holders' incentives. First, we use an option-pricing context to show that CoCo bonds can magnify equity holders' incentives to increase the riskiness of assets and decrease incentives to raise new equity in a crisis in cases in which conversion transfers wealth from CoCo bond holders to equity holders. Second, we present a clinical study of the CoCo bonds issued so far. We show that i) almost all existing CoCo bonds are designed in a way that implies a wealth transfer from CoCo bond holders to equity holders at conversion and ii) this contractual design is reflected in traded prices of CoCo bonds. In particular, CoCo bonds are short volatility with a magnitude five times greater than that which can be observed for straight bonds. These results are robust and economically significant. We conclude that the CoCo bonds issued so far can create perverse incentives for banks' equity holders.
\end{abstract}

Keywords: Contingent capital, banking regulation, risk-taking incentives, asset substitution, debt overhang, credit crunch

*We would like to thank Tim Adam, Hermann Locarek-Junge, Antonio Moreno, Lars Norden, Jörg Rocholl, George Pennacchi (the editor), Rune Stenbacka, Daniel Streitz, the participants of the IRMC 2011 conference in Amsterdam, the Systemic Risk, Basel III, Financial Stability and Regulation Conference 2011 in Sydney, the 2011 conference of the Verein für Socialpolitik in Frankfurt, the 2011 DGF conference in Regensburg (best paper award), the 12th Symposium on Finance, Banking, and Insurance in Karlsruhe, the participants of research seminars in Berlin and at Deutsche Bundesbank, and two anonymous referees for valuable comments and suggestions that helped improve the quality of this paper. All remaining errors are our own. Tobias Berg gratefully acknowledges financial support from the Deutsche Forschungsgemeinschaft through SFB 649 "Economic Risk" and SFB-TR15 "Governance and the Efficiency of Economic Systems".

${ }^{\dagger}$ Corresponding author. 


\section{Introduction}

Contingent convertible capital (CoCo bonds) has been proposed as an instrument to strengthen the resilience of the financial system and to prevent a taxpayer funded bailout of financial institutions. CoCo bonds are debt instruments which automatically convert into equity in cases of financial distress of a single bank and/or the whole financial system. The trigger event is usually defined through the use of a preset regulatory capital ratio (such as the core Tier 1 ratio) falling below a prespecified threshold. Upon conversion, CoCo bond holders receive either a number of shares that is predetermined or that is based on the share price before conversion. The key appeal of CoCo bonds is therefore that it provides an additional source of equity under conditions of distress when other options of raising capital may be extremely costly. ${ }^{1}$ CoCo bonds were initially proposed by Flannery (2002). They recently received considerable attention as potential instruments to ease the impact of future financial crises. Ben Bernanke and Timothy Geithner argued in testimony delivered to Congress in April 2010 that contingent capital can act as a shock absorber that "can be used in a crisis to create more capital" (Geithner (2010)). Contingent capital has also been proposed by the Squam Lake Working Group on Financial Regulation, a group of 15 distinguished academics, to be a way of stabilizing large, systemically important financial institutions. Regulatory proposals have been put forward by the Bank for International Settlements (BCBS (2010)), the European Banking Authority (EBA (2011)) as well as the regulatory body in Switzerland. ${ }^{2}$ Moreover, fourteen European banks already issued CoCo bonds whose total value comes to more than USD 60 billion. If converted, these bonds would increase the capital ratios of these banks by an average of approximately 1 percentage point.

The appeal of providing additional equity capital in times of distress is easy to understand. CoCo bonds do, however, also have an impact on banks' ex ante incentives. This paper makes two main contributions to the discussion on this topic. First, we analyze the effect of the conversion price of CoCo bonds on equity holders' incentives in a structural

\footnotetext{
${ }^{1}$ In particular, equity issuances may themselves be viewed as revealing bad news about the bank, cf. Myers and Majluf (1984), Duffie (2010), and Calomiris and Herring (2013).

${ }^{2}$ The Swiss parliament amended the banking law in 2011 in order to allow banks to have CoCo bonds recognized as part of their regulatory capital.
} 
model of default. Second, we empirically analyze the incentive effects of recent CoCo bond issuances.

We start by analyzing a first-passage time framework in which default and conversion are triggerd by the asset value falling below a prespecified threshold. Standard first-passage time structural models assume that asset values are perfectly observable. However, the measurement of assets can be problematic, in particular for banks and in particular during times of crisis. ${ }^{3}$ We therefore extend our analysis to a model featuring uncertainty about today's asset value, thereby building upon the model of Duffie and Lando (2001). Conversion and default are triggered by the asset value falling below a prespecified threshold. While regulators know the true asset value and will force conversion or default once the threshold is reached, outside equityholders, debtholders, and CoCo bond holders have only imperfect information about the true asset value. The decision about bank viability is frequently decided by regulators. We believe therefore that such a set-up closely mirrors reality.

We show that CoCo bonds exacerbate the asset substitution and debt overhang problem in cases in which the conversion price is set too high, i.e. the number of shares that the CoCo bond holders receive upon conversion is very low. With a high conversion price a wealth transfer from CoCo bond holders to equity holders takes place at the time of conversion. Roughly speaking, equity holders have to bear the initial losses up to an amount of X. They can impose part of the losses on CoCo bond holders once losses exceed X. Equity holders are therefore better off when being directly below the trigger point rather than being directly above the trigger point. They fully participate in any increases in asset value, while they can impose part of the losses in case of a decrease in asset value. This payoff profile induces destabilizing effects: Bank owners have an increased incentive to take excessive risks if the level of risk is non-contractible (asset substitution) and they have a disincentive to raise new equity in a crisis (debt overhang).

We continue by empirically analyzing both the contract design and the pricing of recent CoCo bond issuances. We show that i) all recent CoCo bond issuances use regulatory ratios to trigger conversion, ii) almost all (23 out of 24) issuances have a conversion price

\footnotetext{
${ }^{3}$ Indeed, the main models about the existence of intermediaries crucially depend upon this assumption, cf. for example Diamond (1984).
} 
that induces a wealth transfer from CoCo bond holders to equity holders upon conversion. This mechanism is also reflected in traded prices. CoCo bond holders are significantly short volatility. The magnitude of this negative vega position is far beyond the levels that can be observed for straight bonds. In the case of the Lloyds' CoCo bond issuance we find that the sensitivity of CoCo bond prices to changes in the volatility is five times larger than the respective sensitivity of straight Lloyds bonds with the same maturity.

In the final part of the paper, we discuss several potential explanations for the reasons why market participants have settled on such a design (regulatory trigger and wealth transfer to equity holders upon conversion, with a focus on the latter). Possible explanations range from naive/behavioral motives (perceived threat of dilution, regulators fixated on CoCo bonds absorbing losses), rational explanations (tax deductibility, change of control costs), and institutional and legal frictions (limitations placed on debt investors to hold shares, preference of non-listed banks to use write-down features) to agency-based explanations (managerial risk aversion) and others (provide incentives for prompt loss recognition and disincentives for evergreening of loans). Against the background of limited empirical data, we do not aim to single out one specific explanation. Rather, we want to highlight a simple fact. The great majority of CoCo bond issuances so far is based on regulatory triggers and the design induces a wealth transfer from CoCo bond holders to equity holders upon conversion. We argue that the incentives created by this design do not seem to be in the interest of financial stability.

This paper encompasses three areas of research. First, we draw upon the theoretical literature on the link between capital structure and equity holders' incentives. This link was initially established by Jensen and Meckling (1976) and Myers (1977). According to Jensen and Meckling (1976) equity holders of a levered firm have an incentive to increase risk. This is because they effectively hold a call option on the company's assets (asset substitution problem). The asset substitution problem therefore predicts excessive risktaking in the financial sector and gambling for resurrection in times of a financial crisis (Dewatripont and Tirole (1994)). Myers (1977) has stressed the underinvestment, or debt overhang, problem of firms that are highly levered. A high leverage discourages the firm from issuing new equity. This is because more equity capital increases the value of 
debt, and thus issuing new equity effectively constitutes a transfer of wealth from initial equityholders to debtholders.

Second, there exists a large body of empirical literature on the role of bank incentives in financial crises. Empirical evidence substantiates the existence of the asset substitution problem (Stromberg, Chesney, and Wagner (2010), Fahlenbrach and Stulz (2011), Beltratti and Stulz (2012), Kose, Saunders, and Senbet (2000), Esty (1998), Pontell (2005), and Fukuda, Kasuya, and Nakajima (2006)) as well the debt overhang problem (Bernanke, Lown, and Friedmann (1991), Peek and Rosengren (1995), Hancock, Laing, and Wilcox (1995) for the U.S. and Watanabe (2007) for Japan). These empirical results suggest that incentives do have a first-order consequence for decision making, and wrong incentives did play an important role in previous financial crises.

Third, our paper builds upon the growing literature on contingent capital. First proposed by Flannery (2002), the idea of contingent capital has since been advocated by several authors (Duffie (2010) and Squam Lake Working Group on Financial Regulation (2009)). Several papers derive valuation formulae for contingent capital instruments and discuss key design issues (Pennacchi, Vermaelen, and Wolff (2012), Glasserman and Nouri (2012a), Albul, Jaffee, and Tchistyi (2010), Sundaresan and Wang (2010), Posner (2010), Pennacchi (2011)). Sundaresan and Wang (2010) show that in cases in which conversion is triggered by market values falling below a certain threshold, CoCo bonds generally do not lead to a unique equilibrium for equity and CoCo bond prices. Multiple equilibria can cause problems because market participants might try to manipulate prices to achieve the optimal equilibrium for their holdings (Hillion and Vermaelen (2004)). ${ }^{4}$ Glasserman and Nouri (2012b) show that the possibility of multiple equilibria can be ruled out in cases in which the triggering security is continuously traded and the conversion price is sufficiently low. Pennacchi, Vermaelen, and Wolff (2012) have proposed a new form of contingent capital, labelled Call Option Enhanced Reverse Convertibles (COERCs), which eliminate concerns about a loss spiral. The authors also analyze the effect of COERCs on risk-taking incentives. Calomiris and Herring (2013) provide a similar design feature which allows

\footnotetext{
${ }^{4}$ Davis, Korenok, and Prescott (2011) were the first to analyze market-based triggers in an experimental set-up. They find that, consistent with theory, triggers based on market prices can lead to allocative inefficiencies.
} 
for market-based triggers and still preserves a unique equilibrium. Flannery (2009) also notes that "we must take care that the conversion process does not influence managers to behave in a counter-productive way". This acknowledges the two-sided effects on banks: First, CoCo bonds can help recapitalizing a bank in times of distress. Second, the existence of CoCo bonds themselves can possibly change the way managers behave even before conversion. Flannery (2002, 2009), Maes and Schoutens (2010), Coffee (2010) and Hilscher and Raviv (2011) all recognize that the resulting bank managers' incentives should be taken into account. Coffee (2010) thereby proposes that CoCo bonds should not convert to equity, but to preferred stock with cumulative dividends and voting rights. Thereby a class of shareholders is created which is rationally risk averse. Hilscher and Raviv (2011) show that appropriately designed CoCo bonds are able to cancel out adverse effects of equity-based compensation. Finally, Koziol and Lawrenz (2012) were the first to point out to the asset substitution problem associated with contingent capital when managers endogenously chose the optimal level of contingent capital.

This paper is structured as follows. In Section 2 we explain the driving factors behind our model with a simple case in a single-period set-up. In Section 3 we develop general results in a continuous time Duffie-Lando-type model. In Section 4 we analyze in-depth the CoCo bonds that have been issued so far. Section 5 presents reasons why the CoCo bonds issued so far have been based on regulatory ratios, and why they imply a transfer of wealth from CoCo bond holders to equity holders upon conversion. Section 6 concludes.

\section{A simple example}

For illustrative purposes we start with a simple example, which is depicted in Table 1. A bank whose assets are worth 100 has straight debt of 80, contingent capital of 10 and equity of 10 . The contingent capital converts to equity in cases in which the ratio of equity to assets falls below 5\%. Conversion is therefore triggered when losses of 5 have been accumulated. We further assume that, upon conversion, contingent capital holders receive newly issued shares in an amount equal to the pre-conversion number of outstanding shares (Panel A of Table 1). Thus, contingent capital holders own $50 \%$ of 
the outstanding shares after conversion.

In this set-up the bank's equity holders fully bear the first losses up to $5-\epsilon$ (see columns (1) - (4) in Panel A of Table 1). Once losses exceed 5 (column (5) - (7) in Panel A of Table 1), they can impose part of these losses on contingent capital holders. Equity holders are therefore better off with losses of $5+\epsilon$ (of which they can impose half on contingent capital holders) than with losses of $5-\epsilon$ (which they have to bear fully on their own). For example, the payoff to equity holders for an asset value of 94 is 7 (see column (6) in Panel A of Table 1), while it is only 6 for an asset value of 96 (see column (3) in Panel A of 1).

We define the wealth transfer $W T$ to be the difference between i) the notional value of the CoCo bond and ii) the value of the shares that CoCo bond holders receive upon conversion:

$$
W T=N_{C o C o}-\% \text { SharesCoCo } \cdot \text { MCap@Conversion }
$$

where $W T$ denotes the wealth transfer, $N_{C o C o}$ the notional of the CoCo bonds, $\%$ SharesCoCo the percentage of outstanding shares owned by the CoCo bond holders after conversion and MCap@Conversion denotes the market capitalization directly after conversion has taken place.

In our example, the wealth transfer at conversion from CoCo bond holders to equity holders is equal to $W T=10-50 \% \cdot 15=2.5$. The wealth transfer is equal to the difference in payoff to equityholders just above the trigger point (losses of $5-\epsilon$, equity value is $5+\epsilon$, see column (4) in Table 1) versus just below the trigger point (losses of $5+\epsilon$, equity value is $7.5-\epsilon / 2$, see column (5) in Table 1). A wealth transfer from CoCo bond holders to equity holders means that equity holders are better off with an asset value slightly below the trigger than with asset values slightly above the trigger.

What does the positive wealth transfer from CoCo bond holders to equity holders imply for the incentives of equity holders immediately prior to the triggering of conversion? The first effect is that equity holders are given a strong incentive to increase the riskiness of the bank's assets. With losses of $5-\epsilon$, both a gain of 1 and a loss of 1 will improve the payoff to equity holders. The second effect is that the equity holders now have a marked 
disincentive to raise new equity. Raising equity would push them further away from the conversion threshold. This would therefore decrease the likelihood that they can impose part of the losses on contingent capital holders.

More generally, for any convex payoff function $f\left(V_{T}\right)$ of the asset value $V_{T}$ at time $T$ and a mean-preserving spread $\epsilon$, we can apply the law of iterated expectations and Jensens's inequality:

$$
E\left[f\left(V_{T}+\epsilon\right)\right]>E\left[f\left(V_{T}\right)\right]
$$

Therefore equity holders have an incentive to increase the riskiness of their assets whenever the payoff function is convex in $V_{T}$ (sufficient condition). In a simple Merton (1974) setup, the payoff to equity holders, $f\left(V_{T}\right)=\max \left(V_{T}-D, 0\right)$, where $D$ denotes the notional value of debt, is clearly a convex function of $V_{T}$. Equity holders are thus exposed to an incentive to increase the riskiness of assets.

So, does contingent capital increase risk-taking incentives for equity holders? The answer to this question crucially depends on the conversion price and the wealth transfer that this conversion price implies. A wealth transfer from CoCo bond holders to equity holders at the trigger point means that equity holders are better off for an asset value slightly below the trigger point than for an asset value slightly above the trigger point. They thus prefer to add a mean-preserving spread whenever the current asset value is above the trigger point. The opposite holds for a CoCo bond that implies a wealth transfer from equity holders to CoCo bond holders. A simple example of this opposite case - with a wealth transfer from equity holders to CoCo bond holders at conversion is depicted in Panel B of Table 1, in which CoCo bond holders receive all outstanding shares upon conversion.

\section{Theoretical model}

\subsection{Model set-up and objective function}

In this section, we formulate our model set-up and the equity holders' objective function. 


\subsubsection{Model set-up}

To analyze the incentives from contingent capital we use a structural model of default. Thus, our model set-up consists of three elements: First, an assumption on the asset value process. Second, an assumption on the contract design of deposits and contingent capital (including the definition of when conversion and default occurs). Third, an assumption on equity holders' strategies, i.e. the variables that are endogenous in our model.

Before we formally define these elements, we want to highlight the key assumption that distinguishes our analysis from the previous literature on contingent capital. Our key assumption is that the current asset value can only be observed with noise. ${ }^{5}$ This assumption was first introduced by Duffie and Lando (2001). In their model, the current asset value is a random variable - as opposed to being a fixed number - as it is usually assumed in structural models of default. This assumption is motivated by a simple observation: banks with observable asset values are a contradiction in terms. The very existence of banks is often accounted for by the existence of asymmetric information between borrowers and lenders, and the resulting need for screening and monitoring of borrowers (Diamond and Dybvig (1983), Diamond (1984)). The assumption of observable asset values is incompatible with this theoretical foundation of financial intermediaries. The assumption of unobservable asset values has two important implications. First, as argued above, the assumption is a better reflection of reality than the standard assumption of observable asset values. Second, the assumption provides an endogenous explanation of some of the stylized facts we observe in reality. For example, unobservable asset values can cause jumps in the value of debt and equity even when the full-information asset value follows a continuous process. ${ }^{6}$ The following paragraph sets out our main assumptions in

\footnotetext{
${ }^{5}$ In a related idea, Pennacchi, Vermaelen, and Wolff (2012) extend their COERC-model to encompass mean-reverting deviations of market prices from fundamentals. Our model contains two notable differences: First, we create a model explicitly featuring a two-tiered information structure (we assume that regulators have more information about the true asset value than outside investors). Second, we explicitly model information revelation. In particular investors can learn about the true asset value both by receiving a signal about the true asset value and when certain triggers (conversion, default) are hit. This assumption leads to jumps in the value of contingent claims on the asset value (equity, debt, contingent capital), despite the full-information asset value following a continuous process. Pennacchi, Vermaelen, and Wolff (2012) also allow for jumps by exogenously introducing a jump-component to the asset value process.

${ }^{6} \mathrm{~A}$ typical feature is the fact that models with unobservable asset values can produce a "jump-todefault" behavior and are therefore consistent with reduced-form pricing models (Duffie and Lando (2001)).
} 
more detail:

Assumption 3.1 (Model set-up)

1. (Asset value process) Under the risk-neutral measure, asset values before deposit interest payments are assumed to follow a geometric Brownian $d V_{t}=r V_{t} d t+\sigma V_{t} d B_{t}$ motion with a risk-neutral drift $r$, volatility $\sigma$ and an initial asset value of $V_{0}$ in $t=0$. After a time of $s$, investors receive a signal about the true asset value. Thus, the current asset value $V_{s}$ in $t=s$ cannot be observed directly. Instead investors receive a noisy observation $\hat{V}_{s}$ with $\log \left(\hat{V}_{s}\right)=\log \left(V_{s}\right)+U(s)$ where $U$ is normally distributed with mean $E(U)=0$ and standard deviation $\sigma(U)=\alpha$. The term "investors" refers to both outside equity holders and CoCo bond holders, i.e. both have the same information.

2. (Deposit) The bank has deposits with a constant notional of $N_{\text {Deposits. Deposits have }}$ an instantaneous maturity and pay the risk-free rate $r$.

3. (CoCo bonds) CoCo bonds are assumed to be zero coupon bonds with a maturity $T$ and a notional of $\mathrm{N}_{\mathrm{CoCo}}{ }^{7}$ Conversion of the CoCo bonds takes place when the asset value $V_{t}$ falls below a certain threshold TP ("trigger point") during the maturity of the CoCo bond (first-passage time framework). We consider four benchmark cases for the conversion price. We label these "Convert-to-Steal", "Convert-toSurrender", "Convert-to-Par" and "No CoCo bond".8

- Convert-to-Steal-Type: Upon conversion being triggered, CoCo bond holders are wiped out and equity holders keep $100 \%$ of the equity claim.

- Convert-to-Surrender-Type: Upon conversion being triggered, equity holders are wiped out and CoCo bond holders receive $100 \%$ of the equity claim.

\footnotetext{
${ }^{7}$ The market value of the CoCo bond will differ from the notional value. This is due to i) discounting and ii) the conversion feature of the CoCo bond. In our empirical analysis, we will set the interest rate to $0 \%$, so that discounting does not have an effect on the CoCo bond. However, the market value of the the CoCo bond will differ depending on the conversion terms.

${ }^{8}$ In terms of the conversion price, Convert-to-Steal represents a conversion price of infinity, Convertto-Surrender represents a conversion price of zero and Convert-to-Par represents a conversion price equal to the market price at the time of conversion.
} 
- Convert-to-Par-Type: Upon conversion being triggered, CoCo bond holders receive a fraction $N_{C o C o} /\left(T P-N_{\text {Deposits }}\right)$, so that, at conversion, the value of the shares they receive is equal to the notional value of the CoCo bonds.

- No CoCo bonds: Non-convertible subordinated debt is issued instead of CoCo bonds. The subordinated debt comes in the form of zero coupon bonds with a notional of $N_{\text {SubBond }}$.

We assume that payoffs take place at the time of conversion, default, or maturity. The contract design, including the level of the trigger point, are common knowledge among all market participants.

4. (Default event) Default occurs when the asset value $V_{t}$ falls below the notional value of deposits prior to the maturity T. In that case, equity holders and CoCo bond holders are fully wiped out. In the case of subordinated bonds (instead of CoCo bonds), default occurs when the asset value $V_{t}$ falls below the notional value of the deposits plus the notional value of subordinated debt.

Assumption 1 is taken directly from Duffie and Lando (2001). It allows us to derive the density of the asset value $V_{s}$ conditional on the information filtration available to investors, i.e. $\mathcal{H}_{s}=\sigma\left(\left\{V_{0}, \hat{V}_{s}, 1_{\tau>t}: 0 \leq t \leq s\right\}\right)$. Here, $\tau=\inf \left\{t: V_{t} \leq T P\right\}$ is the first time that the asset value falls below the trigger level $T P$. Intuitively, investors have three pieces of information: First, the noisy observation $\hat{V}_{s}$. Second, the starting value $V_{0}$ at $t=0$. Third, the fact that no conversion or default has taken place between $t=0$ and $t=s$ (i.e. investors cannot observe the asset value, but they can observe default or conversion). We reproduce the conditional density of the current asset value $V_{s}, f\left(x \mid V_{0}, \hat{V}_{s}, s\right)$, in Appendix A. This conditional density has a support of $(T P, \infty]$, i.e. the density is zero for asset values $V_{s} \leq T P$. Setting the asset value uncertainty to zero $(\alpha=0)$ results in a standard Black-Cox-framework (Black and Cox (1976)).

A few points are worth noting here. First, in assumption 1, we assume that all outside investors, i.e. outside equity holders and CoCo bond holders, have the same information. We believe that this assumption best describes the situation for large banks whose equity is widely held, where outside equity holders are unlikely to have an informational advantage 
over debt investors. This assumption requires us to discuss how conversion or default will actually be triggered once the true asset value $V_{t}$ hits the trigger point or the default barrier (assumption 4). In practice, default by banks is usually triggered by regulators and central banks. Our set-up is therefore consistent with regulators observing the true asset value $\left(V_{s}\right)$ and causing conversion and default, and with the "asset-value-as-observed-byinvestors" $\left(\hat{V}_{s}\right)$ being a noisy and unbiased estimate of $V_{s} .{ }^{9}$ We present an extended model containing multiple noisy observations in Appendix B. ${ }^{10}$

Second, in assumption 2, we make the standard assumption of an instantaneous maturity for deposits. In accordance with the empirical evidence of the "stickiness" of deposits, we assume that the notional of deposits is constant over time. Deposits are risk-free in our framework because the regulator triggers default whenever the value of assets reaches the notional of deposits and there are no bankruptcy costs. We therefore assume that deposits earn the risk-free rate. It is mathematically straightforward to introduce flat deposit insurance premia, but, given the structure of our model, no such deposit insurance is necessary.

Third, in assumption 3, we assume that conversion is triggered once the asset value falls below a certain threshold - as opposed to models where conversion is triggered by the market value of equity itself. We assume that the asset value evolves exogenously. Thus, our set-up avoids problems of no equilibrium in cases in which conversion entails a wealth transfer to equity holders (Convert-to-Steal) and in which conversion is triggered by the market value of the bank's equity (Glasserman and Nouri (2012b)). We also explicitly refrain from modeling the amount of straight bonds, the amount of CoCo bonds and the design of CoCo bonds (trigger and conversion price) as an endogenous choice based on taxes, bankruptcy costs and implicit state guarantees. Therefore, we take the view that banks' amount of contingent capital as well as the amount of equity are exogenous

\footnotetext{
${ }^{9}$ Similar to Duffie and Lando (2001), we assume that regulators and inside equity holders are prohibited from trading in equities and CoCo bonds so that information about the true asset value does not reach the secondary market.

${ }^{10}$ Our basic model could be extended to consider a case where regulators have better information than outside investors but still not perfect information regarding the true asset value. For example, regulators might receive a separate noisy signal $\hat{V}_{s}^{r}$ in addition to the noisy signal investors receive. Observing both noisy signals gives regulators more information than investors regarding the true asset value $V_{s}$, but not necessarily perfect information. Hence, regulators can mistakingly convert too early or too late. Such an extended version would also allow to analyze the incentives of managers to increase the opaqueness of assets. We leave this subject for future research.
} 
parameters.

\subsection{Payoff profile and valuation}

Given model assumptions, we are now able to derive formulae for the payoff profile and value of equity in the presence of CoCo bonds.

\subsubsection{Payoff profile}

The payoff to equity holders depends both on the asset value at maturity as well as on the running minimum. In cases in which the running minimum is below the value of deposits (Convert-to-Steal, Convert-to-Surrender, Convert-to-Par) or below the value of deposits plus subordinated debt notional (No CoCo bonds), equity holders receive nothing. In cases of a running minimum above the trigger point, equity holders are simply residual claimants. In the case of intermediate running minimia, equity holders' payoff depends on the existence and type of contingent capital. In the following, we abstract from dividend payments or share buybacks, so that the only payoff equity holders receive is the payoff at maturity $t=s+T$. We denote the payoff to equity holders at time $t$ as $h_{\text {Type }}(t)$, where Type denotes the CoCo bond type (Convert-to-Steal, Convert-to-Surrender, Convert-toPar, No CoCo bonds). Furthermore we denote the first time that the true asset value process $V_{t}$ hits a boundary $B$ by $\tau(B)$. We can thus write these payoffs as:

Convert-to-Steal case:

$$
h_{C-t-\text { Steal }}(t)= \begin{cases}V_{s+T}-N_{\text {Deposits }}-N_{\text {CoCo }}, & t=s+T \wedge \tau(T P)>s+T, \\ V_{\tau(T P)}-N_{\text {Deposits }}, & t=\tau(T P) \wedge \tau(T P) \leq s+T \\ 0, & \text { otherwise }\end{cases}
$$

Convert-to-Surrender case:

$$
h_{C-t-\text { Surr }}(t)= \begin{cases}V_{s+T}-N_{\text {Deposits }}-N_{\text {CoCo }}, & t=s+T \wedge \tau(T P)>s+T, \\ 0, & \text { otherwise }\end{cases}
$$


Convert-to-Par:

$$
h_{C-t-P a r}(t)= \begin{cases}V_{s+T}-N_{\text {Deposits }}-N_{\text {CoCo }}, & t=s+T \wedge \tau(T P)>s+T, \\ V_{\tau(T P)}-N_{\text {Deposits }}-N_{C o C o}, & t=\tau(T P) \wedge \tau(T P) \leq s+T \\ 0, & \text { otherwise }\end{cases}
$$

No CoCo bonds $\left(N_{\text {Dep }+ \text { Sub }}:=N_{\text {Deposits }}+N_{\text {SubDebt }}\right)$ :

$$
h_{\text {NoCoCo }}(t)= \begin{cases}V_{s+T}-N_{\text {Deposits }}-N_{\text {SubDebt }}, & t=s+T \wedge \tau\left(N_{\text {Dep }+ \text { Sub }}\right)>s+T \\ 0, & \text { otherwise }\end{cases}
$$

\subsubsection{Valuation}

The value of shareholder's equity - as seen by outside investors - in the Black-Cox (BC) framework $(\alpha=0)$ for an asset value starting at $V_{s}$ in $t=s$ can be derived using standard risk-neutral valuation methods:

$$
S_{\text {Type }}^{B C}\left(V_{s}\right)=E_{s}^{Q}\left[\int_{s}^{s+T} e^{-r u} h_{\text {Type }}(u) d u\right]
$$

where Type again denotes the respective profile (Convert-to-Steal, Convert-to-Surrender, Convert-to-par, No CoCo bonds). We emphasize the dependence on the asset value $V_{s}$ to highlight the link to the model featuring unobservable asset values. Obviously, (7) depends on the other parameters (risk-free rate, volatility, notional values, maturity) as well. In a Duffie-Lando (DL) framework with unobservable asset value, the equity value can be determined as a weighted average of the Black-Cox values at different asset values $V_{s}$, weighted by the density of the asset value $f\left(x \mid V_{0}, \hat{V}_{s}, s\right)$. The asset value density has a support of $[T P, \infty]$ so that the integral runs from TP to $\infty:{ }^{11}$

$$
S_{\text {Type }}^{D L}\left(\hat{V}_{s}\right)=\int_{T P}^{\infty} S_{\text {Type }}^{B C}(x) f\left(x \mid V_{0}, \hat{V}_{s}, s\right) d x
$$

\footnotetext{
${ }^{11}$ In the case without CoCo bonds, the support is $\left[N_{\text {Deposits }}+N_{\text {SubDebt }}, \infty\right]$.
} 
Terms (7) and (8) can be evaluated using standard Monte Carlo simulation techniques (Boyle (1977)).

\subsubsection{Greeks}

We are interested in the effect of contingent capital on two types of incentives. First, the incentive to increase asset risk (asset substitution problem). Second, the reluctance to provide new funds to conduct zero or positive NPV projects (debt overhang problem). As proxies for these incentives, we use simple derivatives with respect to asset volatility (asset substitution) and the underlying asset value (debt overhang). We derive these derivatives numerically using a symmetric Newton quotient.

\subsection{Numerical illustration}

To illustrate the resulting effects we choose the following parameters:

- The asset value as estimated by investors $\left(E\left[V_{s} \mid \mathcal{H}_{s}\right]\right)$ is set to be 100 . Furthermore, we assume that $V_{0}=\hat{V}_{s}$, i.e. asset value observations by outside investors are equal in $t=0$ and $t=s .^{12}$

- The risk-free rate is set to be $r=0 \%$. Risk-free rates are indeed close to zero at the moment. Another motivation for this assumption is to ensure a constant leverage, i.e. ensure that asset values and the default barrier / trigger point do not drift apart in expectation.

- The notionals are set to $N_{\text {Deposits }}=85$ (straight debt) and $N_{\text {CoCo }}=5$ (CoCo bond $)^{13}$ and the trigger point is set to $T P=95$. This can be interpreted as a capital ratio of $10 \%$, an additional buffer of CoCo bonds equal to $5 \%$ of the (risk-weighted) assets

\footnotetext{
${ }^{12}$ Please note that $E\left[V_{s} \mid \mathcal{H}_{s}\right] \neq \hat{V}_{s}$. As a simple example, consider the case where $V_{0}=95, \hat{V}_{s}=95$, and the trigger point is $T P=95$. Because investors know that conversion has not taken place yet, their best estimate for the current asset value will certainly be higher than 95 . The noisy estimate $\hat{V}_{s}$ could even be lower than the trigger point $T P$.

${ }^{13}$ Please note that the initial market values of the CoCo bond will vary depending on the conversion terms. While it does not change the paper's qualitative results, the different conversion policies would not be comparing exactly equal amounts - in market value terms - of CoCo bonds. Our general conclusion - that Convert-to-Steal and Convert-to-Surrender type CoCo bonds result in different incentives - is not affected by this assumption. We have assumed a zero risk-free rate, so that the value of the CoCo bond has zero drift under the risk-neutral measure.
} 
and a conversion of the CoCo bonds to equity once the capital ratio falls below $5 \%$ (i.e. the assets fall below 95). ${ }^{14}$

- The maturity of the CoCo bonds (and the subordinated debt in the case without CoCo bonds) is set to $T=5$. Recently issued CoCo bonds have maturities of approximately 10 years - meaning that their running maturities average 5 years. We assume that deposits have an instantaneous maturity.

- For those analyses in which asset volatility is set to a fixed value, we use $\sigma=5 \%$. Gropp and Heider (2010) report a mean asset volatility of $3.6 \%$ with a standard deviation of $3.4 \%$ for a sample of banks from the U.S. and EU from 1991-2004. During crisis periods asset volatility is likely to be higher than this unconditional mean.

- We use $s=0.25$ (delayed observation period) and $\alpha=2.5 \%$ (noise in the observation of the true asset value). The values of $s=0.25$ and $\alpha=2.5 \%$ are based on the idea that investors observe true asset values on a quarterly basis $(s=0.25)$ and uncertainty is equal to one half of the annual asset volatility. ${ }^{15}$

This parameter choice results in a risk-neutral probability that the trigger is hit of $15.82 \%$ over a one-year horizon in a Black-Cox model using a $3.6 \%$ asset volatility. It results in a risk-neutral probability that the trigger is hit of $19.10 \%$ over a one-year horizon in a Duffie-Lando model (using a 3.6\% asset volatility, 2.5\% asset value uncertainty, and $s=0.25$ (one quarter) as the delayed observation period). Real-world probabilities are significantly lower.

Figure 1 depicts the equity value as a function of the asset volatility. Without contingent capital and with Convert-to-Par type CoCo bonds, equity holders do not have any incentives to increase the riskiness of assets. This is a result of the barrier option

\footnotetext{
${ }^{14}$ The new Basel III rules require banks to hold capital of 7-10.5\% (depending on which definition of capital is used). Banks are likely to add an additional buffer to ensure that small changes do not directly push them below the regulatory requirements. The Swiss regulator has proposed contingent capital requirements of up to $9 \%$ of risk weighted assets. This, in turn, is likely to be an upper limit for negotiations outside Switzerland. The CoCo bonds issued so far specify either a trigger point of a $5 \%$ capital ratio or a $7 \%$ capital ratio, usually based on core Tier 1 capital.

${ }^{15} \mathrm{~A}$ more sophisticated way, one however requiring the making of further assumptions, would be to use the dispersion of analyst forecasts to estimate the uncertainty about the NPV of the equity claim and transform this into an equivalent uncertainty of the asset value.
} 
set-up and the zero risk-free rate assumption. The Convert-to-Steal-type CoCo bonds significantly increase equity holders' incentives to increase risk, whereas the Convert-toSurrender-type CoCo bonds significantly weaken risk-taking incentives. The results of our calibration are economically significant. By doubling asset volatility from $5 \%$ to $10 \%$, bank managers can increase the value of equity by $7 \%$ in the Convert-to-Steal case, while the value of equity declines by $13 \%$ in the Convert-to-Surrender case.

\section{Insert Figure 1 about here}

Figure 2 shows the vega of the equity value (in percent of the equity value) as a function of the asset value as seen by investors $\left(\hat{V}_{s}\right)$ for all four cases (Convert-to-Steal, Convertto-Surrender, Convert-to-Par, No CoCo bonds). Vega is defined as the partial derivative of the equity value $S_{\text {Type }}^{D L}\left(\hat{V}_{s}\right)$ (see $(8)$ ) with respect to the asset volatility $\sigma$. The results from Figure 1 are confirmed. The Convert-to-Steal-type CoCo bonds significantly increase banks' incentives to increase risk across all asset values, whereas the Convert-to-Surrendertype CoCo bonds significantly decrease risk-taking incentives. In the Convert-to-Steal case, risk-taking incentives are most pronounced for intermediate asset values. For asset values close to the trigger point, the likelihood of the trigger being hit converges to $100 \%$ independent of asset volatility. For large asset values it converges to $0 \%$ independent of asset volatility. In the Convert-to-Surrender case, vega is an increasing function of asset value. This is because we have depicted the vega relative to the equity value. For asset values close to the trigger point, the probability of conversion converges to $100 \%$ in a first-passage time framework. Therefore, the equity value converges to zero in the Convert-to-Surrender case.

\section{Insert Figure 2 about here}

Figure 3 reports deltas, i.e. proxies for the debt overhang problem. Delta is defined as the partial derivative of the equity value $S_{\text {Type }}^{D L}\left(\hat{V}_{s}\right)$ (see $(8)$ ) with respect to the asset value $V_{s}$. A delta smaller than one suggests that an increase in asset value by one unit increases the equity value by less than one unit. Thus, equity holders will usually be reluctant to provide new funds in these cases. A delta larger than one suggests that an 
increase in asset value by one unit increases equity value by more than one unit. Equity holders are thus more likely to be willing to provide new funds. Convert-to-Steal CoCo bonds have a delta smaller than one and thus discourage equity holders from issuing new equity in times of crisis. The reason is that the conversion feature adds value for equity holders, and moving the asset value away from the trigger point therefore decreases equity value. The opposite is true for Convert-to-Surrender CoCo bonds that increase the incentives of equity holders to issue new capital in times of crisis. Deltas are zero for the Convert-to-Par and the Subordinated Bond cases. Furthermore, the wedge in incentives between Convert-to-Surrender and Convert-to-Steal increases closer to the trigger point. For example, directly above the trigger point, a one unit increase in asset values increases equity value by only 0.6 units in the Convert-to-Steal case, but by more than 1.5 in the Convert-to-Surrender case. Thus, equity holders would only be willing to provide new funds in the Convert-to-Steal case in cases in which one additional dollar increases asset values by $1 / 0.6=1.67$. New projects thus need to have very high NPVs to make them worthwhile for equity holders to invest. ${ }^{16}$ The opposite effect can be observed in the Convert-to-Surrender case. It is, however, disputable whether incentives for equity holders to raise new equity are sufficient to ensure the recapitalization of banks in a systemic crisis. However, it does not seem a good idea to explicitly introduce instruments that discourage the issuance of new equity during a crisis. Calomiris and Herring (2013) have proposed a variant of a Convert-to-Surrender bond precisely to give banks an incentive to issue new capital in times of crisis.

\section{Insert Figure 3 about here}

So far, we have looked at a variety of representative calibrations and the extreme cases of Convert-to-Steal and Convert-to-Surrender. What happens with other parameter combinations and CoCo bonds which are in between these two extreme cases? First, while other parameter combinations change the specific numbers, the main message does

\footnotetext{
${ }^{16}$ Delta can even become negative in the Convert-to-Steal case should the size of the CoCo bond be sufficiently large. Furthermore, please note that deltas are derivatives and therefore - by definition only look at a small $\epsilon$-environment around the current asset value. Convert-to-Steal type CoCo bonds can also give incentives to equity holders to destroy value (absent fears of legal actions) in an amount that triggers conversion.
} 
not change. Convert-to-Steal type bonds encourage risk-taking and discourage recapitalization, while the opposite is true for Convert-to-Surrender bonds. These effects are more pronounced for larger CoCo bond notionals (because they determine the one-off gain equity holders can reap at conversion). Vegas for CoCo bonds with a conversion price between Convert-to-Steal and Convert-to-Par or between Convert-to-Par and Convertto-Surrender can be calculated as weighted averages of the two relevant cases. Thus, the asset substitution problem becomes less and less severe when moving from a Convertto-Steal type CoCo bond to a Convert-to-Surrender type CoCo bond, and it "reverses" somewhere in betweeen. As we will discuss in the empirical part, most CoCo bonds issued so far are remarkably close to the Convert-to-Steal case. In the empirical part, we also explicitly analyze the asset substitution problem for CoCo bonds lying in between the two extreme cases discussed here, with the calibration being based on the conversion price of these CoCo bond issuances.

Finally, we have so far failed to consider any aspects that might arise from repeated interactions between equity holders and contingent capital holders. Repeated interactions can dampen conflicts of interest. This is because any misbehavior might be punished during the next interaction. An analytical solution for analyzing incentives in a repeated interaction set-up is beyond the scope of this paper. It is therefore important to point out that our analysis provides ceteris paribus results.

\section{Empirical analysis}

\subsection{Research design and hypotheses}

In this section, we will demonstrate that the contingent capital instruments issued over the past years do indeed give rise to an asset substitution problem. Ideally, such an empirical analysis would follow three steps:

- Contracts: Demonstrate that the contract design of the contingent capital instruments allows equity holders to benefit at the expense of contingent capital bond holders by increasing the riskiness of the bank's assets. 
- Pricing: Show that this contract design is reflected in the prices of contingent capital instruments. In particular, show that contingent capital holders are short volatility.

- Behavior: Show that equity holders react to these incentives in ways postulated in the theory. In particular, prove that the propensity of equity holders to increase the riskiness of their assets is due to contingent capital being part of their capital structure.

We analyze the first and the second points using contingent capital issuances of three major banks over the past years. We do not attempt to analyze the third point in this paper for three reasons. First, the relatively small number of banks that have so far issued contingent capital makes it impossible to draw statistically valid conclusions from a cross-sectional analysis. Second, our time period is short. In particular, it does not include a period where equity ratios are close to the trigger ratios and incentives for asset substitution and gambling for resurrection should be strongest. This puts further strains on observing and identifying behavioral changes. Third, contingent capital issuances are likely to be endogenous. This means that any causal relation between contingent capital issuance and an increase in the riskiness of assets is hard or even impossible to establish.

We start by documenting the stylized fact that the large majority of the contingent capital instruments issued so far entail a wealth transfer from contingent capital holders to equity holders at conversion (Section 4.2). From a principal-agent perspective, such a contract does not seem to be optimal since - following our theoretical model above - such a design would aggravate the asset substitution and debt overhang problem.

Section 4.3 tests a hypothesis regarding the correlation between changes in volatility and returns on contingent capital. The Lloyds contingent capital instruments are public issuances, while other issuances are either private placements (such as the March 2010 Rabobank and the February 2011 Credit Suisse issuances) or have only been issued recently so that little pricing data is available. Our analysis on the pricing of contingent capital will therefore focus on the Lloyds case. 


\subsection{Contract analysis}

\subsubsection{Background on CoCo bond issuances}

Fourteen major European banks issued 24 CoCo bonds between 2009 and $2013 .{ }^{17} \mathrm{~A}$ summary of these issuances can be found in Table 2. Notionals range from 0.3 billion USD (0.25 billion CHF, issued by Credit Suisse) to more than 10 billion USD (Lloyds and Bankia). The first CoCo bond was issued in November 2009 by Lloyds with a total notional of GBP 8.3 billion (USD 13.7 billion) via a (forced) conversion of subordinated debt. Maturities for all CoCo bonds are 10 years or larger and interest rates exceed 5\% in all cases. All triggers are based on regulatory ratios, with the CT1/RWA-ratio being the most frequently used trigger ratio. The CoCo bonds would, if all were fully converted or written down, raise the core Tier 1 ratio by $1.1 \%$. One of the CoCo bonds, the May 2011 issuance by the Bank of Cyprus, was already converted into equity in 2012 and 2013, thereby increasing the core Tier 1 ratio by almost four percentage points. Fourteen of the 24 issuances have a write-down feature - i.e. these CoCo bonds are clearly of the Convert-to-Steal type. ${ }^{18}$ As will be discussed in the next subsection in more detail, almost all CoCo bonds induce a wealth transfer from CoCo bond holders to equity holders upon conversion. Across all banks, this wealth transfer is on average equal to $75 \%$ of the CoCo-notionals or $17 \%$ of the estimated pre-conversion market value of equity (details on the estimation method are provided in the next subsection).

In the following, we describe how we have compiled our estimate of the wealth transfer for four representative issuances in more detail. First is the Lloyds issuance as this was the first and one of the largest issuances. Second is the March 2010 issuance of Rabobank that is written down by $75 \%$ if the Equity/RWA-ratio falls below $7 \%$. Rabobank is not publicly listed - and thus a prime example of a case in which the use of market-based triggers and a conversion into common shares are not possible. Third is the February 2010 Credit Suisse

\footnotetext{
${ }^{17}$ We are not aware of any U.S. issuances so far.

${ }^{18}$ All except four of these CoCo bonds are fully written down once the trigger is hit and are thus the extreme case of a Convert-to-Steal type CoCo bond. The March 2010 Rabobank CoCo bond is written off by $75 \%$, whereas three of the 14 write-down bonds have a write-back clause. The January 2011 issuance by Rabobank is written down by only the amount that is necessary to return the capital ratio to $8 \%$ (similar to the proposal by Glasserman and Nouri (2012a). We still classify this as a full write-down because once the trigger is hit, all losses are borne by the CoCo bond holders and none by the equity holders as long as the notional of the CoCo bond is fully depleted.
} 
issuance, which was issued to fulfill the requirements by the Swiss regulator FINMA. Credit Suisse has been the most active CoCo-issuer so far. It has placed seven issuances totalling 3.8\% of year-end 2013 risk-weighted assets. Fourth is the latest December 2013 issuance by Barclays. Barclays has frequently stated its concerns that the issuance of such bonds could lead to a dilution of existing shareholders. ${ }^{19}$ Consequently, its first issuance in November 2013 will be fully written down, and not converted into equity, if the trigger is hit. Barclay's latest December 2013 issuance converts into common shares, but provides extant shareholders with an option to buy any shares from this conversion at the conversion price, thereby limiting any downside to equity holders from conversion. This design thus shares features with the COERC proposal put forward by Pennacchi, Vermaelen, and Wolff (2012)..$^{20}$

Insert Table 2 about here

\subsubsection{Wealth transfer at conversion}

Section 3 established that the key driver shaping equity holders' incentives is the existence and magnitude of a wealth transfer at conversion. In general, this wealth transfer $W T$ can be determined to be the difference between i) the notional value of the CoCo bond and ii) the value of the shares that CoCo bond holders receive at conversion (see formula (1) in Section 2):

$$
W T=N_{C o C o}-\% \text { SharesCoCo } \cdot M C a p @ \text { Conversion }
$$

where $W T$ denotes the wealth transfer, $N_{C o C o}$ the notional of the CoCo bonds, $\%$ SharesCoCo the percentage of outstanding shares owned by the CoCo bond holders after conversion and MCap@Conversion denotes the market capitalization directly after conversion has taken place.

$N_{C o C o}$ and \% SharesCoCo can be determined directly from the respective prospectus. MCap@Conversion has to be estimated. We make the simplifying assumption that the

\footnotetext{
${ }^{19}$ Cf. Reuters, April 17, 2013, "Barclays CoCo plan seeks to allay investor dilution threat" (accessed via http://uk.reuters.com/article/2013/04/17/uk-barclays-cocos-agm-idUKBRE93G0KO20130417).

${ }^{20}$ Cf. Barclays (2013), page S-16, item "Conversion Shares Offer" for the option to buy back shares from the conversion.
} 
equity value moves one-to-one with the regulatory capital and that risk weighted assets do not change, i.e. changes in capital ratios are only due to changes in capital. For example, if today's capital ratio is $10 \%$ and the trigger is $5 \%$, we assume that the equity value directly above the trigger will also be half of today's equity value. This back-ofthe-envelope calculation is likely to be conservative. First, market values usually decline faster and sooner than Tier 1 ratios due to the stickiness of accounting ratios. Second, accounting ratios are not observed in continuous time meaning that the core Tier 1 ratio at conversion is likely to be lower than $5 \%$. Therefore, these assumptions most likely provide a lower limit for the wealth transfer at conversion. Using these assumptions, the market capitalization after conversion can be determined to be

$$
\text { MCap@Conversion }=\text { MCap today } \frac{\text { TriggerRatio }}{\text { Ratio } o_{\text {today }}}+N_{\text {CoCo }}
$$

where MCap@Conversion denotes the market capitalization directly after conversion, MCap today denotes the market capitalization today, TriggerRatio denotes the capital ratio which triggers conversion ${ }^{21}$, Ratio today denotes the value of the respective ratio today and $N_{C o C o}$ denotes the notional of the CoCo bond. Finally, we link the wealth transfer to both the notional of the CoCo bonds (to get an indication of the loss that CoCo bond holders will experience at conversion) and to the equity value directly above the trigger.

Results are depicted in Table 3 as of December 31, 2013. For example, the Lloyds market capitalization is GBP 56.3 billion and the core Tier 1 ratio is 14.0\%. Our rough estimate of the combined market value of current equity capital and CoCo bonds at the trigger point is 5\%/14.0\% GBP 56.3 billion + GBP 8.3 billion $=28.4$ billion. Hence, the $16 \%$ share of the CoCo bond holders will be worth approximately GBP 4.6 billion - which is a $44 \%$ discount on the nominal value and $18 \%$ of the equity value directly above the trigger. The wealth transfer in percent of the CoCo notional is even larger for the Rabobank CoCo bond (75\%) and lower (31\%) in the case of Credit Suisse. Barclays' issuance is closer to a Convert-to-Par type CoCo bonds. In our simplified calculation, the

\footnotetext{
${ }^{21}$ This ratio is the core Tier 1 ratio in case of Lloyds, Credit Suisse and Barclays. It is the equity ratio - a simpler measure which is roughly equal to balance sheet equity capital divided by risk-weighted assets - in case of Rabobank.
} 
shares that CoCo bond holders receive upon conversion are even worth more than the CoCo bond notional. Given that extant shareholders have the right to buy back these shares at the conversion price, the wealth transfer is bounded at zero. Please note that all these calculations are likely to be overly positive for CoCo bond holders: Should the decline in market values exceed that of regulatory ratios, even in Barclays case contingent capital holders might face significant losses upon conversion.

What does that mean for incentives? First of all, if, for example, Lloyds is close to the trigger then an increase in asset value of GBP 3.5 billion is a worse outcome for shareholders than a slight decrease of asset values and a subsequent conversion of CoCo bonds into equity. This is because a conversion results in a GBP 3.6 billion windfall profit for shareholders. These numbers suggest that generating stable positive profits in times of a crisis is not in the interest of shareholders and that risk-shifting is likely to take place. Even worse, there is a huge disincentive for shareholders to recapitalize the bank on their own. Directly above the trigger point, an injection of new funds equal to GBP 3.5 billion will have the same effect in terms of the extant shareholders' wealth as experiencing a further decline of one pound and subsequently hitting the trigger. Roughly speaking, the first GBP 3.5 billion of capital injections in times of distress are sunk costs for old shareholders. This injection of funds therefore has to be hugely profitable. If not, equity holders will refrain from recapitalizing their bank and will wait until conversion is triggered. In view of the fact that regulatory capital ratios are slowly moving, this may give rise to a long period of underinvestment and limited credit supply.

Insert Table 3 about here

\subsubsection{A detailed assessment of the Lloyds issuance}

In the following, we analyze the incentive effects arising from the Lloyds' issuance in more detail. We thereby make the following assumptions:

- Assumptions as in Section 3 (Black-Cox-Duffie-Lando framework and main parameters). 
- The maturity is set to be 5 years, the average remaining maturity of a 10-year CoCo bond.

- Changes in the Tier 1 ratio can only be induced by gains/losses. This precludes changes in RWA via increased/decreased business volume, via changes in average risk weight, and via new equity issuances. ${ }^{22}$

- The market value of equity moves one-to-one with the core Tier 1 capital, meaning that a $10 \%$ drop in the core Tier 1 ratio results in a $10 \%$ drop in the market value of equity.

- All values are as of December 31, 2013.

- The assets are set to be equal to the risk-weighted assets of GBP 263.9 billion and the equity is set to be equal to the market capitalization (GBP 56.3 billion). The $5 \%$ core Tier 1 ratio trigger thus translates into a loss of $(1-35.7 \%) \cdot$ GBP 56.3 billion = GBP 36.2 billion (see Table 3 for the derivation of the $35.7 \%$ loss figure) and a CoCo bond trigger of GBP 263.9 billion - GBP 36.2 billion = GBP 227.7 billion. From Tables 2 and 3, we use a notional of the CoCo bonds of GBP 8.3 billion and assume that CoCo bond holders own $16 \%$ of the after-conversion equity.

Figure 4 depicts the magnitude of the asset substitution problem (left-hand picture) as well as the magnitude of the debt overhang problem (right-hand picture). We observe two main results. The first is that CoCo bonds are very close to the Convert-to-Steal case from an incentive point of view. Second, the asset substitution problem and the debt overhang problem are greatly exacerbated by the existence of CoCo bonds. Due to the CoCo bonds, equity holders have a significant interest in increasing the riskiness of the portfolio. An increase of the asset volatility by 1 percentage point translates into an increase in equity value of up to $1 \%$. No less worrisome is the debt overhang problem. An increase in NPV of up to USD 1.10 per USD 1 investment is needed to make it beneficial for equity holders to inject more capital.

\footnotetext{
${ }^{22}$ For reasons of simplification, we also do not take into account a manipulation of risk-weights. See Mariathasana and Merrouche (2014) for a detailed analysis of risk-weight manipulation by banks.
} 
All these numbers are most definitely lower bounds. First, we have made a very conservative assumption that in times of financial distress share prices only fall by the same amount as the regulatory capital ratios. Should share prices decline earlier and sharper, then the transfer of wealth at conversion will be even greater. This further exacerbates both the asset substitution and the debt overhang problem. Second, Lloyds has only GBP 8.3 billion of CoCo bonds outstanding - compared to RWA of GBP 263.9 billion (approximately 3\%). If regulators force banks to hold larger amounts of CoCo bonds of the Convert-to-Steal-type, the incentive to "gamble for resurrection or conversion" and the disincentive to raise new equity in times of distress will be further aggravated.

Insert Figure 4 about here

\subsection{Pricing}

We now test the relationship between CoCo bond returns and changes in volatility. We run a time-series regression:

$$
r_{C o C o, t}=\beta_{0}+\beta_{1} \Delta \sigma_{t}+\beta_{2} Y_{t}+\epsilon_{t}
$$

where $r_{C o C o, t}$ is the total return of the contingent capital from $t-1$ to $t, \Delta \sigma_{t}$ is the change in volatility from $t-1$ to $t$, and $Y_{t}$ are control variables. We use the following set-up:

- For $r_{C o C o, t}$, we use the weekly total return from the Lloyds contingent capital issue with the ISIN XS0459086582 taken from Bloomberg over the period from November 30, 2009 to December 31, 2012. This issue matures in May 2020. It is the largest single series, and has the most liquid pricing data available. ${ }^{23}$

- For $\Delta \sigma_{t}$, we use the change in the 6-months implied equity volatility from at-themoney put options on Lloyds shares taken from Bloomberg multiplied by the ratio of equity market capitalization to risk-weighted assets. Under simplifying assumptions,

\footnotetext{
${ }^{23}$ We use Bloomberg CBBT prices, which are based on executable prices. A comparison with data from Datastream and Bloomberg Generic Prices (BGN) yields correlations of the total returns above 90\%. Also, the number of non-trading dates based on Bloomberg information is less than 5\%, meaning that prices seem to reflect real trading activity.
} 
the multiplication by the ratio of market capitalization to risk-weighted assets transforms the implied equity volatility to an implied volatility of risk-weighted assets. ${ }^{24}$ We use the 6-months series because it is the longest maturity which is consistently available.

- For $Y_{t}$ we use a) the total return index of a straight bond of Lloyds with the same maturity taken from Bloomberg ${ }^{25}$ and b) the total return on Lloyds equity taken from Bloomberg. Using the total return on a straight bond gives us information on the asset substitution problem beyond that already incorporated in the use of straight bonds and controls for a possible correlation with the risk-free rate. Using the total return on Lloyds equity controls for potential correlation between changes in implied volatility and changes to the asset value of Lloyds.

A correlation matrix of all variables is shown in Table 4. The correlation matrix reveals that, univariately, the total return on contingent capital is highly negatively correlated with changes in the implied volatility $(-0.54, p<0.0001)$. As expected it is positively correlated with the straight bond $(0.53, p<0.0001)$ and with the equity return $(0.47$, $p<0.0001)$. Furthermore, the contingent capital is more negatively correlated with changes in the implied volatility $(-0.54)$ than the straight bond $(-0.28)$. This is a first indication that contingent capital is indeed short volatility beyond the level from the straight bond.

Insert Table 4 about here

Figure 5 provides a two-way scatterplot of changes in volatility and the return on both CoCo bonds and the straight bond. The sensitivity of the CoCo bond total return with

\footnotetext{
${ }^{24}$ See Gropp and Heider (2010) for a similar transformation of equity volatility to asset volatility. This simplified transformation assumes that debt is risk-free. Vassalou and Xing (2004) provide an interative procedure that does not rely on this assumption, however, for deep-in-the-money call options - as in the case of equity as a call option on assets - the resulting asset volatility estimates are very similar. The average ratio of market capitalization to risk-weighted assets is 13.63 , with a standard deviation of 3.52 . Therefore, the implied volatility of risk-weighted assets is more than a factor 10 smaller than the implied equity volatility. Apart from a level effect, this transformation does not have any significant effect on our results. The ratio of market capitalization to risk-weighted assets does not vary much over a weekly interval, and thus weekly changes in the volatility of risk-weighted assets are largely driven by weekly changes in implied equity volatility.

${ }^{25}$ There is no straight bond of Lloyds maturing in May 2012. We therefore use a weighted average of the total returns of the October 2018 (ISIN: XS039513935) and April 2024 (ISIN: XS0422704071) straight bonds. Both of these bonds are fixed rate bonds.
} 
respect to changes in implied volatility is approximately five times larger (-6.54) than the corresponding sensitivity on the straight bond (-1.33). Changes in implied volatility also have a higher explanatory power for CoCo bond total returns than for straight bond total returns ( $R^{2}$ of $29 \%$ vs. $8 \%$ ). This provides further indication that increases in volatility cause a much larger decrease in the value of CoCo bonds than in the value of straight bonds.

\section{Insert Figure 5 about here}

Our results might be spurious due to a correlation of changes in the implied volatility with the asset or equity value. If changes in the implied volatility are negatively correlated with equity returns (as we can see from Table 4), then the negative correlation of CoCo bond returns and changes to the implied volatility might not be a vega effect, but a delta effect. We therefore run the multivariate regression (11) using weekly CoCo bond returns and a standard least-square estimator with robust standard errors. ${ }^{26}$ All results are presented in Table 5. Column (1) only includes changes to the implied volatility as an independent variable, column (2) adds the bond total return and column (3) adds the equity total return.

\section{Insert Table 5 about here}

The total return on the contingent capital bond is significantly correlated with changes to implied volatility in all specifications. An increase in implied volatility of the riskweighted assets by 1 percentage point is associated with a decrease in the value of contingent capital in the range of $2.6 \%$ to $6.5 \%$. Taking $2.6 \%$ (column (3)) to be a conservative estimate of the sensitivity, this implies a decrease in the value of contingent capital of roughly GBP 220 million $(=2.6 \% \cdot 8.3$ billion $)$.

Taken together, there is clear empirical evidence that the major CoCo bonds issued so far entail a wealth transfer at conversion from contingent capital holders to equity holders. For contingent capital issued by Lloyds, we find robust evidence that this contract design

\footnotetext{
${ }^{26}$ We have conducted several robustness tests. In particular, our results are robust to using monthly CoCo bond returns, quantile regression, and including squared terms of the independent variables. Results are available upon request.
} 
is reflected in traded security prices. In particular, CoCo bonds are short volatility. Hence, Convert-to-Steal-type contingent capital may induce agency problems and cause a change in behavior towards a gambling for resurrection or gambling for conversion if banks are close to the trigger ratio.

\section{Discussion}

The empirical facts from the prior section seem puzzling given the adverse incentives that can arise from a Convert-to-Steal design and regulatory ratios. These contracts do not even seem to be second-best from an incentive point of view. See for example Calomiris and Herring (2013) for a discussion. However, other factors might well play a role that offset the negative incentive effects of these type of CoCo bonds. Given that CoCo bonds are a relatively new financing instrument, one could argue that the market is still in its learning phase. So it might simply be a matter of time until a more efficient CoCo bond design emerges. Below, we provide some possible reasons of why CoCo bond issuances have so far used the Convert-to-Steal design with a regulatory trigger.

\subsection{Convert-to-Steal design}

Naive/behavioral explanations: The Convert-to-Steal design might be explained with behavioral arguments. Naive equity holders might be concerned about dilution - without fully recognizing the costs of higher interest rates that come along with it. CoCo bond holders might put too much weight on the probability of conversion - and might disregard the losses ensuing from conversion. Agencies' ratings are usually based on a probability-ofdefault concept - as opposed to an expected-loss-concept. Any CoCo-investor who naively makes investments based on probability-of-default-based ratings will thus underappreciate the role of the conversion price. Institutional rules that limit the amount investors (e.g. insurance companies) can invest in certain rating categories can provide further support for this (Becker and Ivashina (2013)). In a similar spirit, naive regulators might be fixated on CoCos "absorbing losses". Regulators might be preoccupied with avoiding the situation arising in the last crisis, in which nonconvertible subordinated debt did not, 
in most cases, absorb losses. However, it is not necessary for CoCos to absorb losses at the time of conversion for the bank to be recapitalized (since the initial equityholders can absorb the losses). Naive regulators might simply miss this point.

Rational explanations: Change of control costs would provide a rationale for the Convert-to-Steal-design. Similar to bankruptcy costs, any change in the (majority) ownership of a bank might induce costs, and these costs are likely to be more severe in a downturn. To see how this might work, consider the case of a conservative insurance company gaining control during a financial crisis over Goldman Sachs. The question arises: how would this change the strategic orientation of Goldman Sachs? Should a change of control be eminent, key bank employees are usually prevented from walking away by being promised bonus guarantees and retention awards. Such awards are simply an indirect cost of a change in control. ${ }^{27}$ With Convert-to-Steal CoCo bonds, change of control is avoided. This is because CoCo bond holders do not receive any shares. In Appendix C, we present a limited-scope model that details how change of controls costs can rationalize Convert-to-Steal design. In a similar spirit, some shareholders such as strategic investors might put a control premium on having sufficient voting rights to influence the bank's decisions. These investors might even accept a higher cost for CoCo bonds if control premia are sufficiently valuable to them. ${ }^{28}$ Last but not least, there should not be any doubt about the tax deductibility of interest payments on Convert-to-Steal-type CoCo bonds - as these are never converted into shares. The tax treatment of other types of CoCo bonds is less clear in most jurisdictions (Avdjiev, Kartasheva, and Bogdanova (September 2013)). ${ }^{29}$

\footnotetext{
${ }^{27}$ For example, top bankers from Dresdner Bank were promised bonuses and retention awards when taken over by Commerzbank. Commerzbank later unsuccesfully challenged these awards in court, see http://www.theguardian.com/business/2013/apr/26/commerzbank-bankers-paid-bonuses-court (accessed February 14th, 2014).

${ }^{28}$ See Zingales (1994) and La Porta, Lopez-De-Silanes, Shleifer, and Vishny (2002) on the value of control premia. In theory, investors who value control might simply buy back sufficient shares after conversion so as to regain control. However, should they face a binding net worth constraint, they might not have sufficient funds to do so in a crisis.

${ }^{29}$ The importance of the tax treatment as a motive for issuing CoCo bonds is underpinned by the so-called tax redemption clause. For example, Barclays' prospectus of the December 2013 issuance states that Barclays may "redeem the Securities [...] if [...] we would not be entitled to claim a deduction in respect of any payments in computing our taxation liabilities." In Germany, there have not been any issuance of CoCo bonds until end of 2013, a fact that - according to industry representatives - is
} 
Institutional and legal frictions: Many institutional investors face legal or contractual restrictions on holdings of common shares. With Convert-to-Surrender CoCo bonds, CoCo-investors receive a large proportion of outstanding shares upon conversion. They thus might have to sell these shares on short notice in an illiquid market. For banks that are not listed, it might even be impossible to issue contingent capital that converts into common equity. This is not just a theoretical concern. Rabobank is a primary example of a systemically important bank that is not publicly listed. Furthermore, only 41 out of the 124 Eurozone banks subject to ECB supervision are publicly listed; though admittedly, most of the largest ones (Acharya and Steffen (2014)).

Agency-based explanations: Last but not least, the dominance of Convert-to-Steal type CoCo bonds is consistent with an agency-based explanation of managerial risk aversion. Convert-to-Steal-type CoCo bonds dampen the volatility of shareholder wealth by reducing shareholder wealth in the upside (due to higher interest payments on Convert-to-Steal bonds than on Convert-to-Surrencer CoCo bonds) and increasing it in the downside (via write-down of the CoCo bonds). A risk-averse CEO whose compensation depends on the extant shareholders' wealth would thus prefer Convert-to-Steal-tye CoCo bonds, even if it decreases total firm value. ${ }^{30}$ Even risk-neutral CEOs may choose Convert-to-Steal type CoCo bonds should they are faced with a concave incentive scheme. In particular, CEOs might lose their jobs should the stock perform poorly. Shareholders will be less angry at them, ex-post, following a decline in the banking firm's net worth. Of course, the bank will end up paying higher promised interest on CoCo bonds under this design, but the resulting decrease in CEO compensation might be better than the ex-post loss of their jobs from the bank managers' point of view.

related to the uncertain tax treatment of coupon payments on CoCo bonds (see Linklaters (2011)) and an article in Manager Magazin ("Tax problem thwarts capital raising efforts of German banks", available in German via http://www.manager-magazin.de/immobilien/artikel/steuerstreit-bei-pflichtwandelanleihenbremst-deutsche-banken-aus-a-945735.html).

${ }^{30}$ Needless to say, as in the case for all agency-based explanations, informational frictions do have to exist that do not enable shareholders to clearly distinguish between the drivers of a bank's performance and thus design a more granular compensation scheme for CEOs. See Stulz (1984) for a formal model. 
Other explanations: Contingent capital featuring regulatory triggers that transfers wealth from CoCo bond holders to equityholders upon conversion provides equity holders with incentives to quickly write down assets and to correctly reflect the riskiness of the remaining assets in their calculations of regulatory risk-weighted-assets. If regulators are worried about evergreening of loans (Peek and Rosengren (2005)) or about a too optimistic calculation of regulatory risk weights, then Convert-to-Steal-type CoCo bonds might help to counterbalance these incentives. Needless to say, Convert-to-Steal-type CoCo bonds (as compared to other CoCo bond types) provide an incentive for excessive write-downs and very conservative determination of regulatory risk weights. This means that any related argument relies on an asymmetry in the social costs induced by too optimistic versus too conservative balance sheet valuations.

\subsection{Regulatory triggers}

Academics have usually called for market-based triggers (cf. Flannery (2002), Pennacchi, Vermaelen, and Wolff (2012), and Calomiris and Herring (2013), among others). The obvious advantage is that a market-based trigger is publicly and timely observable. Why do all CoCo bonds issued so far use triggers based on regulatory ratios? In the case where regulators have superior knowledge about the fundamental asset value based on their priveleged access to bank-internal information, regulators might be able to separate the bad banks (who are in need of additional equity capital) from the good banks (who are not). In this regulator-friendly view, regulator would use their information to force bad banks to realize losses and to subsequently convert the contingent capital if the regulatory capital ratio falls below the trigger. Should the conversion of contingent capital incur real costs, then such a selective conversion of contingent capital - facilitated by an omniscient regulator - could be optimal.

However, the experience of the past crisis does not necessarily support such a view. Even if regulators have superior knowledge about banks' asset quality, regulators face their own set of incentives which might tilt them towards forbearance. If one accepts the need for Convert-to-Steal type CoCo bonds (based on any of the arguments of the previous subsection) then there is another explanation why banks choose regulatory triggers. In 
the case of Convert-to-Steal, market based equity triggers can result in a no-equilibrium situation (Sundaresan and Wang (2010) and Glasserman and Nouri (2012b)). Regulatory triggers can - if the regulatory ratio is exogenous and does not itself depend on equity values - avoid such a no-equilibrium situation. However, as shown by Pennacchi, Vermaelen, and Wolff (2012), a market value of total capital (equity plus CoCo bonds) has a unique equilibrium as well. Thus, a regulatory trigger is by no means the only mechanism that avoids the no-equilibrium situation.

A less benign argument for regulatory triggers is that shareholders and CoCo bond holders believe that the bank is able to manipulate the regulatory trigger. This means that CoCo bonds will never convert, and that they resemble subordinated debt. While regulators believe they are a form of capital, they are not effectively able to recapitalize banks in the next crisis (see Haldane (2011) for the susceptibility of risk-weights to manipulation). As anecdotal evidence, information about Barclays' contingent capital issuances is presented on its "Debt investors" section of the investor relation webpage. In its issuance announcement, Barclays stresses the positive effect of this issuance on the CRD IV leverage ratio. ${ }^{31}$ As Calomiris and Herring (2013) point out, even during the financial crisis, a regulatory capital trigger of $7 \%$ would not have been hit by many of the large US banks. This is not only due to the fact that risk-weighted assets can be subject to manipulation, but also to accounting rules, which cause market prices to be imperfectly and belatedly reflected in book values.

Finally, and for obvious reasons, market-based triggers cannot work if a bank is not listed. This is not a minor concern, not even for systemically important banks: As dicsussed above, only 41 out of the 124 Eurozone banks subject to ECB supervision are publicly listed (Acharya and Steffen (2014)). Thus, market-based triggers are feasible for only a third of the major Eurozone banks; though admittedly, most of the largest ones.

The target of this paper is not to single out one of these explanations for Convert-toSteal type CoCo bonds or regulatory triggers. It is, rather, to present a simple empirical fact. The large majority of contingent capital instruments issued so far is of the Convertto-Steal type with a regulatory trigger. Prices of these CoCo bonds also suggest that

\footnotetext{
${ }^{31}$ See http://www.newsroom.barclays.com/imagelibrary/downloadMedia.ashx?MediaDetailsID=5978 for the annoucement of the December 2013 contingent capital issuance.
} 
market participants are aware of the effects of this design. CoCo bonds are short volatility with a magnitude five times larger than what can be observed for straight bonds. Such a design can have perverse incentives on risk-taking, and further research is necessary to pin down the exact reason why market participants have so far settled on this design.

\section{Conclusion}

In this paper we have analyzed the effect of the conversion price of CoCo bonds on equity holders' incentives. We have used a Duffie-Lando type model to show that, if the conversion price is set so that conversion redistributes wealth from CoCo bond holders to shareholders, perverse incentives arise. In particular, equity holders have an incentive to increase the riskiness of assets (asset substitution) as well as a disincentive to raise new equity in a crisis (debt overhang).

Our clinical analysis demonstrates that existing CoCo bonds exclusively use regulatory triggers and are designed to transfer wealth from CoCo bond holders to equity holders upon conversion. We found that holders of the Lloyds CoCo bond are short volatility with a magnitude five times greater than that which can be observed for straight bonds. We also discussed several potential explanations as to why market participants have settled on such a design. We do not draw the conclusion that CoCo bonds should not be a part of a bank's capital structure. Rather, our analysis suggests that it is highly important to set the conversion price in a way that does not induce a redistribution of wealth from CoCo bond holders to equity holders upon conversion. Conversely, a conversion price that induces some wealth transfer from equity holders to CoCo bond holders could help to mitigate risk-shifting incentives already present in the current capital structure of banks. It could therefore help to mitigate asset substitution and debt overhang problems. 


\section{References}

Acharya, V. V., And S. Steffen (2014): "Falling short of expectations? Stress-testing the European banking system," Voxeu.org.

Albul, B., D. M. Jaffee, And A. TChistyi (2010): "Contingent convertible bonds and capital structure decisions," Working Paper.

Altman, E. (1984): "A further empirical investigation of the bankruptcy cost question," The Journal of Finance, 39(4), 1067-1089.

Andrade, G., And S. Kaplan (1998): "How costly is financial (not economic) distress? Evidence from highly leveraged transactions that became distressed," The Journal of Finance, 53(5), 1443-1493.

Avdjiev, S., A. Kartasheva, and B. Bogdanova (September 2013): "CoCos: A Primer," BIS Quarterly Review.

Barclays (2013): "Prospectus Supplement to Prospectus dated September 6, 2013," Discussion paper.

BCBS (2010): "Consultative Document: Proposal to ensure the loss absorbency of regulatory capital at the point of non-viability," Discussion paper, Bank for International Settlements.

Becker, B., And V. Ivashina (2013): "Reaching for yield in the bond market," Journal of Finance (forthcoming).

Beltratti, A., And R. M. Stulz (2012): "The credit crisis around the globe: Why did some banks perform better?," Journal of Financial Economics, 105(1), 1-228.

Bernanke, B., C. S. Lown, and B. M. Friedmann (1991): "The credit crunch," Brooking Papers on Economic Activity, 2, 205-247.

Black, F., And J. C. Cox (1976): "Valuing corporate securities: Some effects of bond indenture provisions," The Journal of Finance, 31(2), 351-367. 
Boyle, P. P. (1977): "Options: A monte carlo approach," Journal of Financial Economics, 4(3), 323-338.

Calomiris, C., and R. Herring (2013): "How to Design a Contingent Convertible Debt Requirement That Helps Solve Our Too-Big-to-Fail Problem," Journal of Applied Corporate Finance, 25(2), 39-62.

Coffee, J. C. (2010): "Bail-ins versus bail-outs: Using contingent capital to mitigate systemic risk," Working Paper.

Davis, D., O. Korenok, and E. S. Prescott (2011): "An experimental analysis of contingent capital triggering mechanisms," Working Paper.

Dewatripont, M., and J. Tirole (1994): The prudential regulation of banks. Cambridge, MA.

DiAmond, D. W. (1984): "Financial intermediation and delegated monitoring," The Review of Economic Studies, 51(3), 393-414.

Diamond, D. W., and P. H. Dybvig (1983): "Bank runs, deposit insurance, and liquidity," The Journal of Political Economy, pp. 401-419.

DuffiE, D. (2010): "A contractual approach to restructuring financial institutions," in Ending Government Bailouts as We Know Them, edited by G. Schultz, K. Scott, and J. Taylor, Hoover Institute Press, Stanford University.

Duffie, D., And D. LANDo (2001): "Term structures of credit spreads with incomplete accounting information," Econometrica, 69, 633-664.

EBA (2011): "Buffer Convertible Securities," Discussion paper, European Banking Authority.

Esty, B. C. (1998): "The impact of contingent liability on commercial bank risk taking," Journal of Financial Economics, 47(2), 189-218.

FAhlenbrach, R., And R. M. Stulz (2011): "Bank CEO incentives and the credit crisis," Journal of Financial Economics, 99(1), 11-26. 
Flannery, M. J. (2002): "No pain, no gain: Effecting market discipline via reverse convertible debentures," Working Paper, subsequently published in Hal S. Scott (ed.), Capital adequacy beyond Basel: Banking, securities, and insurance (Oxford: Oxford University Press, 2005).

(2009): "Stabilizing large financial institutions with contingent capital certificates," Working Paper.

Fukuda, S.-I., M. Kasuya, And J. NAKajima (2006): "Deteriorating bank health and lending in Japan: Evidence from unlisted companies under financial distress," Journal of the Asia Pacific Economy, 11(4), 482-501.

Geithner, T. (2010): “Treasury Secretary Tim Geithner Written Testimony before the House Financial Services Committee," Discussion paper, U.S. Department of Treasury (accessed via http://www.treasury.gov/press-center/press-releases/Pages/tg645.aspx).

Glasserman, P., And B. Nouri (2012a): "Contingent capital with a capital-ratio trigger," Management Science, 58(10), 1816-1833.

(2012b): "Market-Triggered Changes in Capital Structure: Equilibrium Price Dynamics," Working Paper.

Gropp, R., And F. Heider (2010): "The Determinants of Bank Capital Structure," Review of Finance, 14(4), 587-622.

Haldane, A. (2011): "Capital Discipline," Speech by Andrew Haldane, available via http://www.bankofengland.co.uk/publications/Documents/speeches/2011/speech484.pdf.

Hancock, D., A. J. LAing, And J. A. Wilcox (1995): "Bank capital shocks: Dynamic effects on securities, loans, and capital," Journal of Banking \& Finance, 19, $661-677$.

Hillion, P., And T. Vermaelen (2004): "Death spiral convertibles," Journal of Financial Economics, 71(2), 381-415. 
Hilscher, J., And A. RAviv (2011): "Bank stability and market discipline: The effect of contingent capital on risk taking and default probability," Working Paper.

Jensen, M. C., And W. H. Meckling (1976): "Theory of the firm. Managerial behavior, agency costs and ownership structure," Journal of Financial Economics, 3(4), 305-360.

Kose, J., A. Saunders, and L. W. Senbet (2000): "A theory of bank regulation and management compensation," Review of Financial Studies, 13(1), 95-126.

Koziol, C., And J. Lawrenz (2012): "Contigent convertibles: Solving or seeding the next banking crisis," Journal of Banking and Finance, 36(1), 90-104.

La Porta, R., F. Lopez-De-Silanes, A. Shleifer, and R. Vishny (2002): "Investor Protection and Corporate Valuation," The Journal of Finance, 57(3), 1147-1170.

Linklaters (2011): “Tax treatment of Tier 1 instruments following Basel III," Discussion paper.

Maes, S., And W. Schoutens (2010): "Contingent capital: an in-depth discussion," Working Paper.

Mariathasana, M., and O. Merrouche (2014): "The Manipulation of Basel RiskWeights," Journal of Financial Intermediation.

Myers, S. C. (1977): "Determinants of corporate borrowing," Journal of Financial Economics, 5(2), 147-175.

Myers, S. C., And N. S. Majluf (1984): "Corporate financing and investment decisions when firms have information investors do not have," Journal of Financial Economics, 13(2), 187-221.

Peek, J., And E. Rosengren (1995): "Bank regulation and the credit crunch," Journal of Banking \& Finance, 19, 679-692.

Peek, J., And E. Rosengren (2005): "Unnatural Selection: Perverse Incentives and the Misallocation of Credit in Japan," American Economic Review, 95(4), 1144-1166. 
Pennacchi, G. (2011): "A structural model of contingent bank capital," Working Paper.

Pennacchi, G., T. Vermaelen, and C. C. Wolff (2012): "Contingent capital: The case for COERCs," Journal of Financial and Quantative Analysis (forthcoming).

Pontell, H. N. (2005): "Control fraud, gambling for resurrection, and moral hazard: Accounting for white-collar crime in the savings and loan crisis," Journal of SocioEconomics, 34(6), 756-770.

Posner, K. A. (2010): "Thoughts on The Squam Lake Report: Reengineering the financial system to better withstand extreme volatility," Journal of Applied Corporate Finance, 22(3), 34-40.

Squam Lake Working Group on Financial Regulation (2009): "An expedited resolution mechanism for distressed financial firms: Regulatory hybrid securities," Discussion paper, Council on Foreign Relations, Center for Geoeconomic Studies.

Stromberg, J., M. Chesney, and A. Wagner (2010): "Risk-taking incentives, governance, and losses in the financial crisis," Workng Paper.

Stulz, R. M. (1984): "Optimal hedging policies," Journal of Financial and Quantative Analysis, 19, 127-140.

Sundaresan, S., And Z. WAng (2010): "Design of contingent capital with a stock price trigger for mandatory conversion," Working Paper.

Vassalou, M., And Y. Xing (2004): "Default risk in equity returns," Journal of Finance, 59, 831-868.

Watanabe, W. (2007): "Prudential regulation and the credit crunch: Evidence from Japan," Journal of Money, Credit \& Banking, 39, 639-665.

ZingaLES, L. (1994): "The value of the voting right: a study of the Milan Stock Exchange experience," Review of Financial Studies, 7(1), 125-148. 


\section{Figure 1: Value of equity as a function of asset volatility in the presence of contingent capital}

This figure shows the equity value as a function of the asset volatility for all four cases (Convert-to-Steal, Convert-to-Surrender, Convert-to-Par, No CoCo bonds). The x-axis shows the asset volatility, the y-axis shows the equity value. Other parameter values are: $T=5$, $s=0.25, r=0 \%, \alpha=1.25 \%, N_{\text {Deposits }}=85, N_{C o C o}=5, T P=95, E\left[V_{s} \mid V_{0}, \hat{V}_{s}, \tau>t\right]=100$.

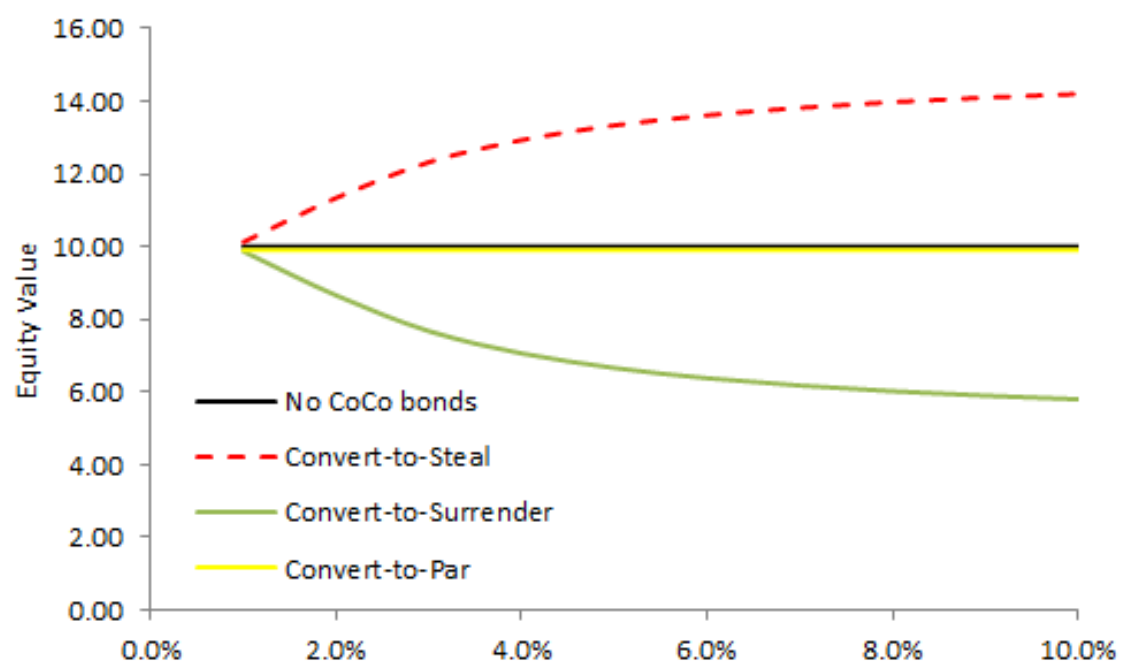

\section{Figure 2: Asset substitution problem in the presence of contingent capital}

This figure shows the vega of the equity value (in percent of the equity value) as a function of the asset value as seen by investors $\left(\hat{V}_{s}\right)$ for all four cases (Convert-to-Steal, Convert-to-Surrender, Convert-to-Par, No CoCo bonds). Vega is defined as the partial derivative of the equity value $S_{\text {Type }}^{D L}\left(\hat{V}_{s}\right)$ (see (8)) with respect to the asset volatility $\sigma$. The $\mathrm{x}$-axis shows the asset value as seen by investors $\left(\hat{V}_{s}\right)$, the y-axis shows the vega of the equity value. Other parameter values are: $T=5, s=0.25, \sigma=5 \%, r=0 \%, \alpha=1.25 \%$, $N_{\text {Deposits }}=85, N_{\text {CoCo }}=5, T P=95$.

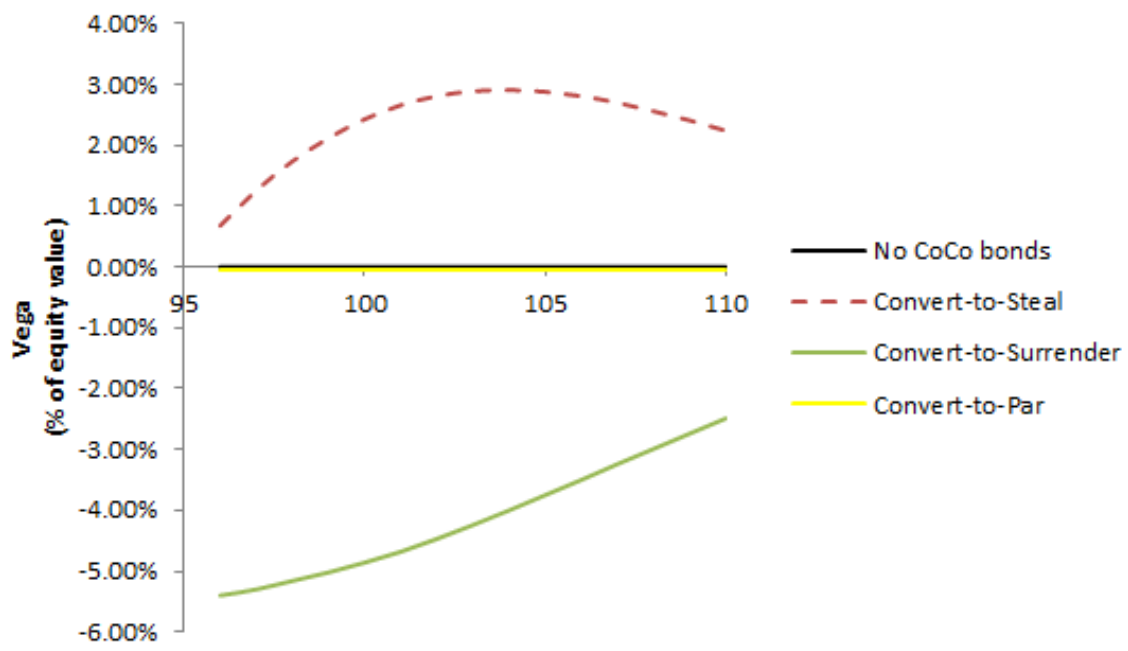




\section{Figure 3: Debt overhang problem in the presence of contingent capital}

This figure shows the delta of the equity value as a function of the asset value as seen by investors $\left(\hat{V}_{s}\right)$ for all four cases (Convert-to-Steal, Convert-to-Surrender, Convert-to-Par, No CoCo bonds). Delta is defined as the partial derivative of the equity value $S_{\text {Type }}^{D L}\left(\hat{V}_{s}\right)$ (see (8)) with respect to the asset value $V_{s}$. The x-axis shows the asset value as seen by investors $\left(\hat{V}_{s}\right)$, the y-axis shows the delta of the equity value. Other parameter values are: $T=5, s=0.25$, $\sigma=5 \%, r=0 \%, \alpha=1.25 \%, N_{\text {Deposits }}=85, N_{C o C o}=5, T P=95$.

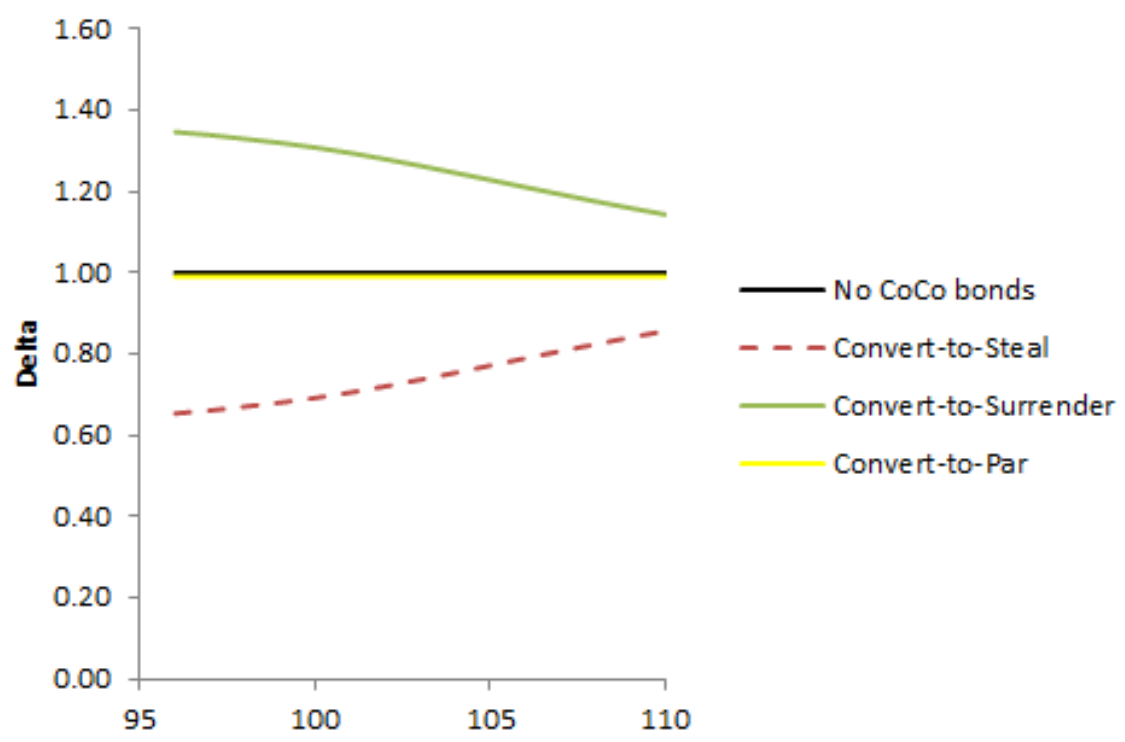




\section{Figure 4: Asset substitution and debt overhang problem for Lloyds}

This figure presents results for the asset substitution and debt overhang problem for Lloyds. The left-hand picture shows the vega of the equity value (in percent of the equity value) as a function of the asset value as seen by investors $\left(\hat{V}_{s}\right)$ for all four cases (Convert-to-Steal, Convert-to-Surrender, Convert-to-Par, No CoCo bonds). The right-hand picture shows the delta of the equity value as a function of the asset value as seen by investors $\left(\hat{V}_{s}\right)$ for all four cases (Convert-to-Steal, Convert-to-Surrender, Convert-to-Par, No CoCo bonds). The x-axis shows the asset value as seen by investors $\left(\hat{V}_{s}\right)$, the y-axis shows the vega in percent of the equity value (left-hand picture) and delta (right-hand picture) of the equity value. Other parameter values are: $T=5, s=0.25, \sigma=5 \%, r=0 \%, \alpha=1.25 \%, N_{\text {Deposits }}=199.34$, $N_{C o C o}=8.3, T P=227.7$.

Figure 4a: Asset substitution

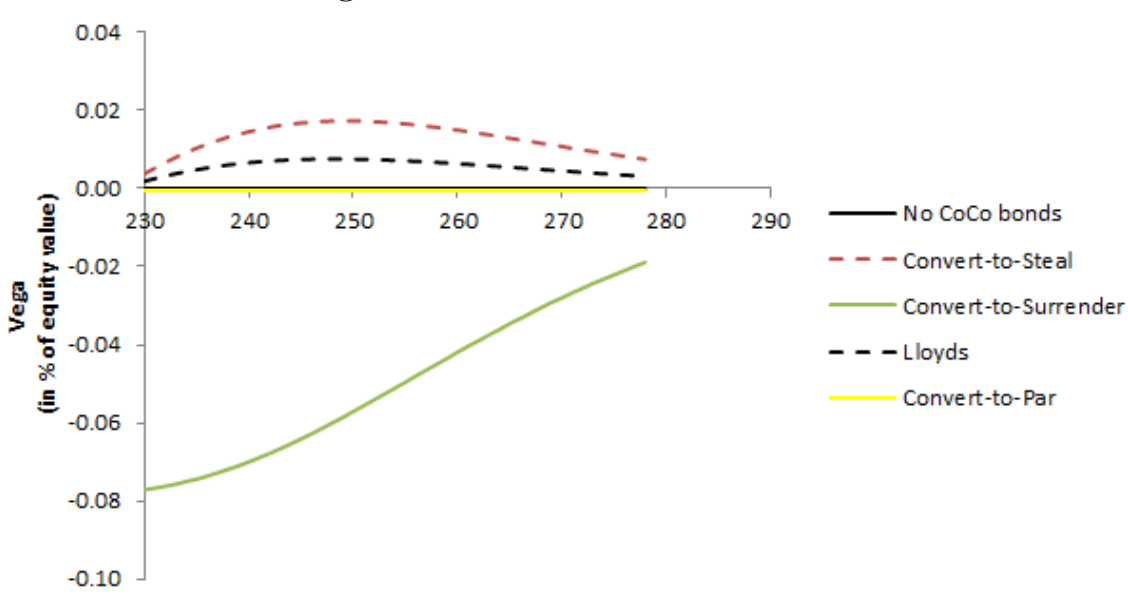

Figure 4b: Debt overhang

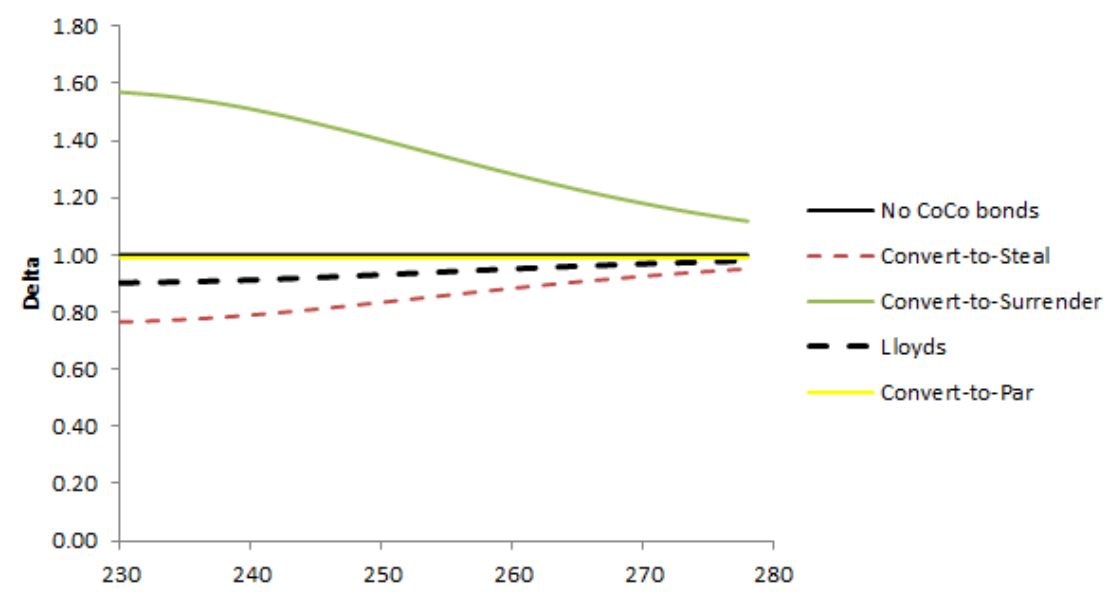




\section{Figure 5: CoCo bond total return, bond total return and implied volatility}

The figure at the top presents a two-way scatterplot for changes to the implied volatility (x-axis) and the CoCo bond total return (y-axis). The figure at the bottom presents a two-way scatterplot for changes to the implied volatility (x-axis) and the straight bond total return (y-axis). Both figures are based on weekly data from December 2009 - December 2012. CoCo bond Total Return denotes the total return on the Lloyds CoCo bonds taken from Bloomberg. $\Delta$ Implied Volatility (unlev) denotes the changes in the unlevered implied volatility, measured as the change in the implied volatility of 6 -months at-the-money put options taken from Bloomberg multiplied by the ratio of market capitalization to risk-weighted assets. Bond Total Return denotes the weighted total return on the October 2018-maturity Lloyds straight bond and the April 2024-maturity Lloyds straight bonds. The weights are 47/66 and 19/66 as to yield the same weighted maturity as the CoCo bonds.
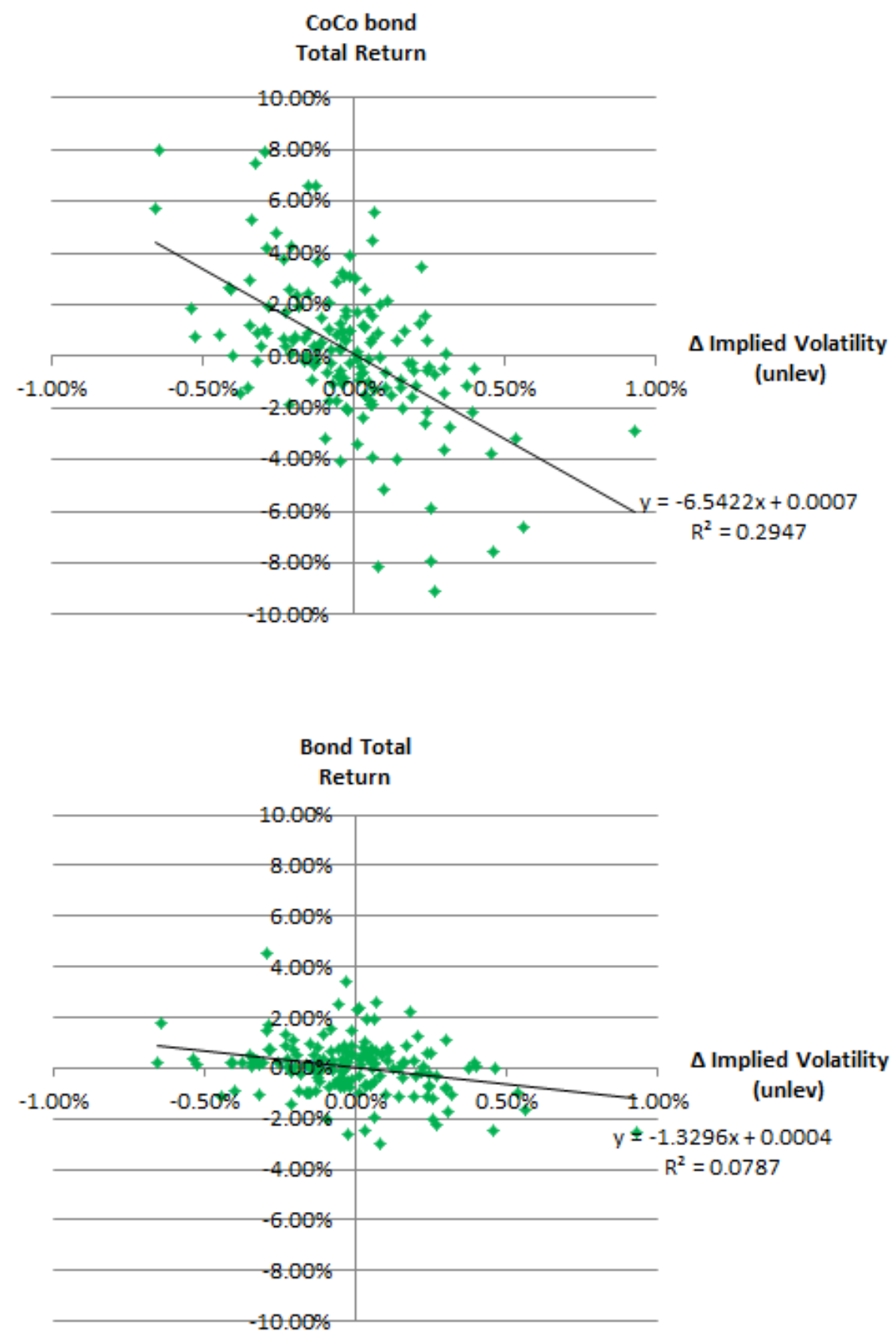


\section{Table 1: Example}

This table provides an illustrative example. The bank's balance sheet consists of 100 . These are financed by 80 straight debt, 10 contingent capital and 10 equity. Conversion is triggered if losses exceed 5. In Panel A, upon conversion, contingent capital holders receive newly issued shares in an amount equal to the pre-conversion number of outstanding shares (i.e., contingent capital holders hold $50 \%$ of the after-conversion outstanding shares). In Panel B, upon conversion, contingent capital holders receive an infinite amount of newly issued shares (i.e., contingent capital holders hold $100 \%$ of the after-conversion outstanding shares).

Panel A (Wealth transfer from CoCo bond holders to equity holders)

(4)

\begin{tabular}{lccccccc}
\hline Value of assets & 100 & 98 & 96 & $95+\epsilon$ & $95-\epsilon$ & 94 & 92 \\
\hline Value Equity & 10 & 8 & 6 & $5+\epsilon$ & $7.5-\epsilon / 2$ & 7 & 6 \\
Value CoCo & 10 & 10 & 10 & 10 & $7.5-\epsilon / 2$ & 7 & 6 \\
Value Debt & 80 & 80 & 80 & 80 & 80 & 80 & 80
\end{tabular}

\begin{tabular}{llllcccc}
\hline Asset losses & 0 & 2 & 4 & $5-\epsilon$ & $5+\epsilon$ & 6 & 8 \\
\hline Equity losses & 0 & 2 & 4 & $5-\epsilon$ & $2.5+\epsilon / 2$ & 3 & 4 \\
CoCo losses & 0 & 0 & 0 & 0 & $2.5+\epsilon / 2$ & 3 & 4 \\
Debt losses & 0 & 0 & 0 & 0 & 0 & 0 & 0 \\
\hline
\end{tabular}

Panel B (Wealth transfer from CoCo bond holders to equity holders)

(1)

$(2)$

$(3)$

$(4)$

$(5)$

(6)

$(7)$

\begin{tabular}{lccccccc}
\hline Value of assets & 100 & 98 & 96 & $95+\epsilon$ & $95-\epsilon$ & 94 & 92 \\
\hline Value Equity & 10 & 8 & 6 & $5+\epsilon$ & 0 & 0 & 0 \\
Value CoCo & 10 & 10 & 10 & 10 & $15-\epsilon$ & 14 & 12 \\
Value Debt & 80 & 80 & 80 & 80 & 80 & 80 & 80
\end{tabular}

\begin{tabular}{lccccccc}
\hline Asset losses & 0 & 2 & 4 & $5-\epsilon$ & $5+\epsilon$ & 6 & 8 \\
\hline Equity losses & 0 & 2 & 4 & $5-\epsilon$ & 10 & 10 & 10 \\
CoCo losses & 0 & 0 & 0 & 0 & $-5+\epsilon$ & -4 & -2 \\
Debt losses & 0 & 0 & 0 & 0 & 0 & 0 & 0 \\
\hline
\end{tabular}




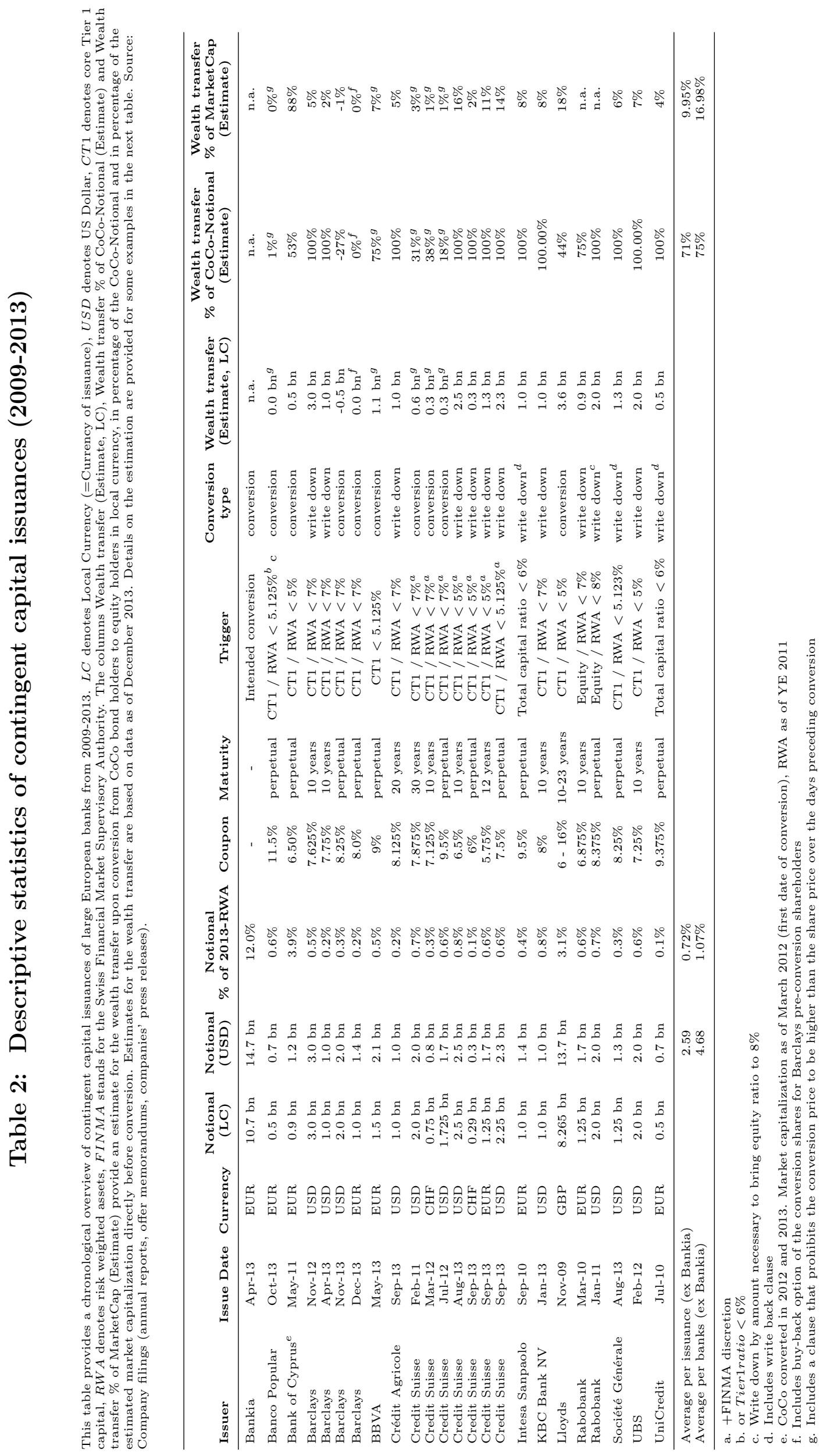




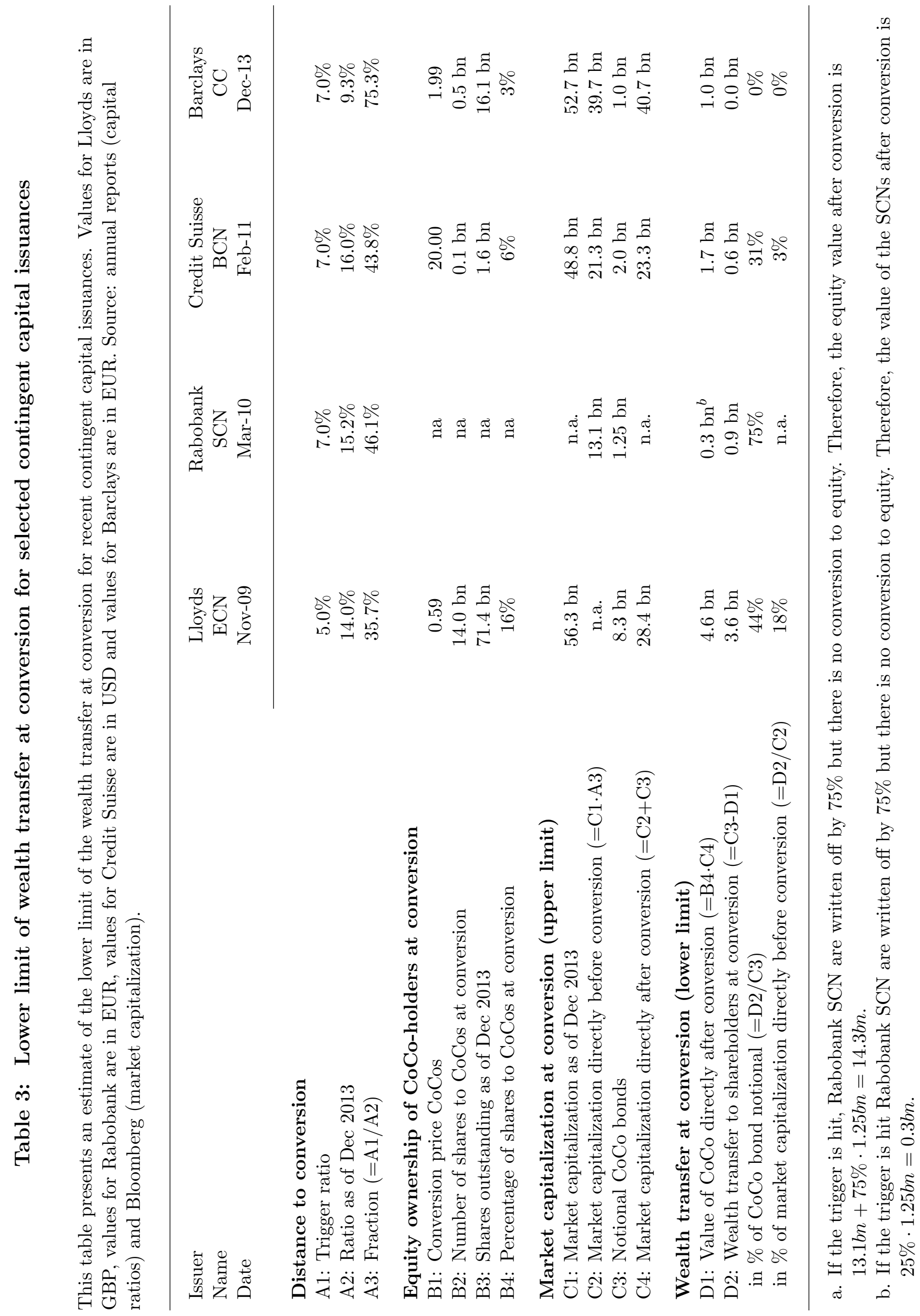




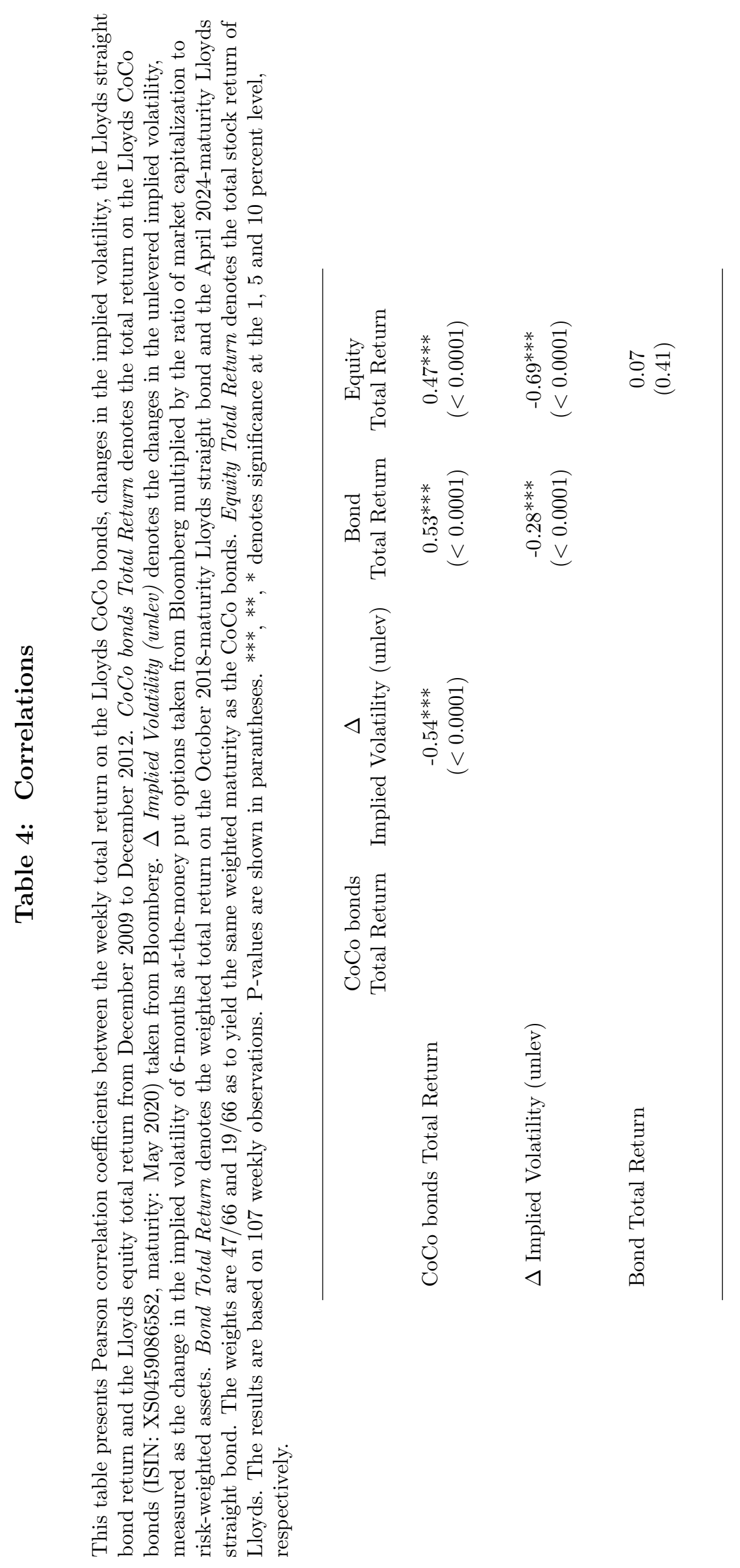




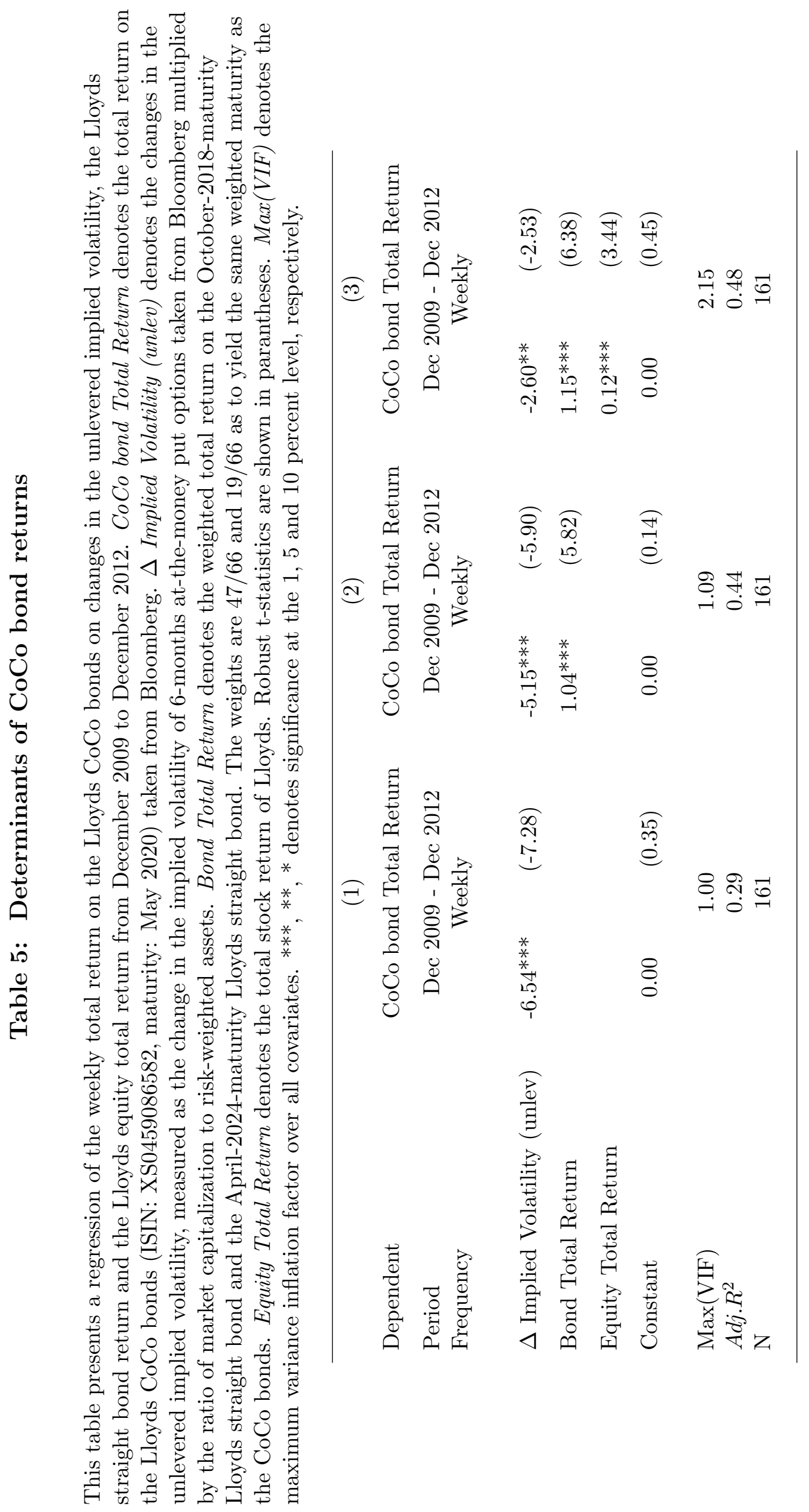




\section{A Density of the asset value}

In this section, we reproduce the results of the density of the asset value from Duffie and Lando (2001). We denote the $\log$-asset value by $z_{t}=\log \left(V_{t}\right)$. The log-asset value follows a Brownian motion with drift $m=r-q-0.5 \sigma^{2}$ and volatility $\sigma$. The log-asset value in $t=0$ is denoted by $z_{0}$ and the noisy observation of the log-asset value in $t=s$ as $y_{s}=\log \left(\hat{V}_{s}\right)=\log \left(V_{s}\right)+U(s)$, where $U(s)$ is normally distributed with mean zero and standard deviation $\alpha$. Investors information set contains the starting value $z_{0}$, the noisy observation $y_{s}$, and the fact that the asset value process has not been "killed" at the boundary $H$ between $t=0$ and $t=s$. Using these notations, the conditional density $g\left(x \mid z_{0}, y_{s}, s\right)$ of the log-asset value $z_{s}=\ln \left(V_{s}\right)$ can be derived as: ${ }^{32}$

$$
g\left(x \mid z_{0}, y_{s}, s\right)=\frac{\sqrt{\frac{\beta_{0}}{\pi}} e^{-J\left(\tilde{y}, \tilde{x}, \tilde{z_{0}}\right)}\left[1-\exp \left(\frac{-2 \tilde{z_{o}} \tilde{x}}{\sigma^{2} s}\right)\right]}{\exp \left(\frac{\beta_{1}^{2}}{4 \beta_{0}}-\beta_{3}\right) \Phi\left(\frac{\beta_{1}}{\sqrt{2 \beta_{0}}}\right)-\exp \left(\frac{\beta_{2}^{2}}{4 \beta_{0}}-\beta_{3}\right) \Phi\left(-\frac{\beta_{2}}{\sqrt{2 \beta_{0}}}\right)}
$$

where

$$
\begin{aligned}
\tilde{y} & =y_{s}-\underline{\nu}, \tilde{x}=x-\underline{\nu}, \tilde{z_{0}}=z_{0}-\underline{\nu} \\
\underline{\nu} & =\log (H) \\
J\left(\tilde{y}, \tilde{x}, \tilde{z_{0}}\right) & =\frac{(\tilde{y}-\tilde{x})^{2}}{2 \alpha^{2}}+\frac{\left(\tilde{z_{0}}+m s-\tilde{x}\right)^{2}}{2 \sigma^{2} s} \\
m & =r-q-0.5 \sigma^{2} \\
\beta_{0} & =\frac{\alpha^{2}+\sigma^{2} s}{2 \alpha^{2} \sigma^{2} s} \\
\beta_{1} & =\frac{\tilde{y}}{\alpha^{2}}+\frac{\tilde{z_{0}}+m s}{\sigma^{2} s} \\
\beta_{2} & =-\beta_{1}+2 \frac{\tilde{z_{0}}}{\sigma^{2} s} \\
\beta_{3} & =\frac{1}{2}\left(\frac{\tilde{y}^{2}}{\alpha^{2}}+\frac{\left(z_{0}+m s\right)^{2}}{\sigma^{2} s}\right)
\end{aligned}
$$

The density of the asset value $V_{s}$ can be easily derived from the density of the log asset value via

$$
f\left(x \mid V_{0}, \hat{V}_{s}, s\right)=g\left(\ln (x) \mid \ln \left(V_{0}\right), \ln \left(\hat{V}_{s}\right), s\right) .
$$

\footnotetext{
${ }^{32}$ Cf. Duffie and Lando (2001)
} 


\section{B Several periods of signals}

In Section 3.1.1 and Appendix A, we have used a single noisy signal $\hat{V}_{s}$ in $t=s$ and the starting asset value in $t=0$ to derive the density of the asset value. From a model point of view, it is straigtforward to allow for several noisy observations of the asset value over time. The information filtration available to investors with one noisy signal $\hat{V}_{s}$, knowledge about the starting value $V_{0}$ and survival up to $t=s$ is $\mathcal{H}_{s}=\sigma\left(\left\{V_{0}, \hat{V}_{s}, 1_{\tau>t}: 0 \leq t \leq s\right\}\right)$. The information filtration available to investors with $N$ noisy signals $\hat{V}_{s_{i}}, 1 \leq i \leq N$ is $\mathcal{H}_{s_{i}}=\sigma\left(\left\{V_{0}, \hat{V}_{s_{i}}, 1_{\tau>t}: 0 \leq t \leq s, 1 \leq i \leq N\right\}\right)$

While conditioning on one noisy signal (i.e. $\mathcal{H}_{s}$ ) allows us to derive a closed-form solution for the conditional density $f\left(x \mid V_{0}, \hat{V}_{s}, s\right)$ of the asset value (see Appendix A), no closed-form solution exists for more than one noisy signal. Using the assumption of uncorrelated accounting noise, Duffie and Lando (2001) derive a formula for the asset value conditional on $N>1$ noisy signals that can be evaluated using numerical integration techniques (see Section 3.2 of Duffie and Lando (2001)). In Figure B.1, we reproduce Figures 2 and 3 using two noisy signals in two subsequent quarters. All other parameters are identical to those chosen in Section 3.3. Results are very similar for both vega and delta. Qualitatively, there are two important effects. First, because the last non-noisy asset value observation is two quarters old (and not just one quarter), the conditional density has a higher variance. Second, for a given time interval, two noisy observations render the asset value estimation more precise, thus lowering the conditional density of the asset value. In our numerical example, the first slightly outweighs the latter effect, but net differences are very small.

\section{Modeling the cost of a change in control}

In this section, we model the equilibrium CoCo bond type when there are change of control costs. We assume that a bank operates with an asset volatility of $\sigma_{0}$. It can choose to invest in a risky project that would increase asset volatility to $\sigma_{u}>\sigma_{0}$. For example, it might be faced with the decision to pursue a merger or not, to start trading commodity derivatives in addition to the lower-risk interest rate and FX derivatives, or to enter the 
subprime mortgage market. The amount of debt and contingent capital the bank has to hold are regulated. The bank therefore faces only two decisions:

- First, whether to use Convert-to-Steal or Convert-to-Par type contingent capital. We rule out Convert-to-Surrender type contingent capital and any intermediate conversion ratios for now, but we will discuss these below.

- Second, should it risk-shift or not. We assume that the bank faces a digital choice $\sigma \in\left\{\sigma_{0}, \sigma_{u}\right\}$ and discuss extensions below.

We introduce two frictions. First, the risky project has a negative NPV. The assets are worth $V_{s}$ in $t=s$ without the risky project. The assets are, however, worth only $(1-\beta) V_{s}$ (with $\beta>0$ ) with the risky project. We do not claim that risky projects always reduce NPV, but this is the interesting case to look at for our application. Second, conversion of the Convert-to-Par type bonds results in change of control costs equal to $\psi \cdot T P$. The economic rationale behind these costs is similar to indirect costs of financial distress (Altman (1984), Andrade and Kaplan (1998)). Both customers and employees might not want to take the risk of dealing with a bank whose future strategic alignment is uncertain. Should a conservative and risk-averse CoCo bond holder suddenly take control, the question arises: will high-risk business areas be closed even though they are positive NPV? Do the new owners of the bank have sufficient industry knowledge to appoint the right board members and take the right decisions? These questions might be of particular importance during a crisis, which are the times when conversion is most likely. ${ }^{33}$ Please note that change of control does not necessarily mean that CoCo bond holders own the majority of outstanding shares, but simply that their holdings are large enough to grant them a significant influence on the bank's management. The fraction of shares necessary to do so may thus depend on corporate governance mechanisms, laws and how widely dispersed equity and contingent capital has been held.

Equity holders' objective is to choose the type of CoCo bond (Convert-to-Steal, Convertto-Par) and volatility $\left(\sigma_{0}, \sigma_{u}\right)$ that maximize the equity value plus the proceeds from

\footnotetext{
${ }^{33}$ One may argue that conversion would seem to indicate that management has not run the bank very well. However, in line with the principle that thieves are the ones best suited to advise one on how to prevent burglaries, those that have gotten the bank into trouble might be the only ones capable of getting it out of it.
} 
selling CoCo bonds. The volatility, as it is not contractible, is chosen as to maximize the equity holders' claim. We further assume that CoCo bond holders correctly anticipate equity holders' incentives to risk-shift. Thus, using slightly informal notations, we can write the equity holders' optimization problem as:

$$
\begin{array}{cc}
\max _{\text {Type }} & \text { EquityValue }(\text { Type }, \bar{\sigma})+\text { CoCoProceeds }(\text { Type }, \bar{\sigma}) \\
& \text { s.t. } \bar{\sigma}=\underset{\sigma}{\arg \max } \operatorname{EquityValue}(\text { Type }, \sigma)
\end{array}
$$

The trade off faced by equity holders is as follows. If they choose Convert-to-Par type CoCo bonds, then buyers of these bonds will factor in expected change of control costs $\psi \cdot T P \cdot \operatorname{Prob}($ Conversion) when pricing contingent capital. Ceteris paribus this reduces proceeds from selling the CoCo bonds. If they choose Convert-to-Steal type CoCo bonds, equity holders may have incentives to risk-shift. Risk-shifting decreases the value of assets (but increases their volatility), so that equity holders will risk-shift with Convert-to-Steal type CoCo bonds whenever the vega-effect (higher equity value due to higher volatility) outweighs the delta effect (lower asset value due to inefficient investment).

Table C.1 provides a specific example using the same parameters as in Section 3.3 and value $\beta=0.01, \psi=0.03, \sigma_{0}=0.05$, and $\sigma_{u}=0.075$. The optimal solution according to (C.1) is depicted in the last column. If asset volatility were contractible, Convert-to-Steal without risk-shifting would always be optimal (no change of control costs, no costs from value-destroying risk-shifting). The optimal solution in the case where asset volatility is non-contractible is as follows:

- Convert-to-Steal without risk-shifting for low asset values: For asset values below or equal to 102, vega is not large enough to outweigh the loss in asset value from riskshifting (values in column (2) are larger than in column (3)). ${ }^{34}$ Thus, Convert-toSteal avoids change of control costs without the drawback of inefficient risk-shifting.

- Convert-to-Steal with risk-shifting for intermediate asset values: For asset values between 103 and 107, vega is so large that equity holders prefer to engage in asset-

\footnotetext{
${ }^{34}$ In the extreme case, when assets are arbitrarily close to the trigger point, the probability of hitting the threshold is equal to $100 \%$ independent of asset volatility.
} 
value-destroying risk-shifting. Convert-to-Par style CoCo bonds are not a viable alternative in this area, because the likelihood of a conversion, and thus the likelihood of incurring costs of change of control $\psi$ are too large (values in column (1) are lower than values in column (4)).

- Convert-to-Par without risk-shifting for high asset values: For asset values between 108 and 113, the likelihood of conversion is low enough to make the Convert-to-Par CoCo bonds without risk-shifting superior to the Convert-to-Steal CoCo bonds with risk-shifting.

- Convert-to-Steal without risk-shifting for very high asset values: For asset values above 113, the call option of equity holders is deep in the money, meaning that Vega is very low. Therefore, the costs of a reduced asset value due to risk-shifting outweigh the benefits arising from the convex pay-off profile. Equity holders can thus credibly commit not to risk-shift, and the optimal solution is therefore a Convert-to-Steal type CoCo bond without risk-shifting.

We have assumed so far that equity holders can only choose between Convert-to-Steal type CoCo bonds and Convert-to-Par type CoCo bonds. Convert-to-Surrender type CoCo bonds do not offer any advantage in this set-up, so they can be ignored without loss of generality. One could easily extend the model to allow for intermediate versions between Convert-to-Steal and Convert-to-Par by specifying $\psi$ to be an increasing function of the percentage of shares held by CoCo bond holders after conversion. A similar argument applies for the asset volatility. An extension to a continous choice of asset volatilities is straightforward if we specify $\beta$ as an increasing function of the asset volatility with $\beta\left(\sigma_{0}\right)=0$. One could even go further and incorporate taxes and bankruptcy costs in the model. If taxes are sufficiently high and interest payments on CoCo bonds are taxdeductible, then CoCo bonds can be superior to equity financing. On the other hand, if bankruptcy costs are sufficiently large, CoCo bonds will be superior to straight bonds. The type of CoCo (Convert-to-Steal versus Convert-to-Par) would then again be governed by the trade-off between change of control costs and asset substitution costs. 


\section{Figure B.1: Vega and delta with two noisy asset value observations}

This figure shows the vega and delta as a function of the current asset value $V_{s}$ for all four cases (Convert-to-Steal, Convert-to-Surrender, Convert-to-Par, No CoCo bonds) in cases in which there are two noisy observations of the asset value. Parameter values are: $T=5$, $s=0.25, \sigma=5 \%, r=0 \%, \alpha=1.25 \%, N_{\text {Deposits }}=85, N_{C o C o}=5, T P=95, \hat{V}_{s 1}=\hat{V}_{s 2}$, $E\left[V_{s} \mid V_{0}, \hat{V}_{s 1}, \hat{V}_{s 2}, \tau>t\right]=100$.
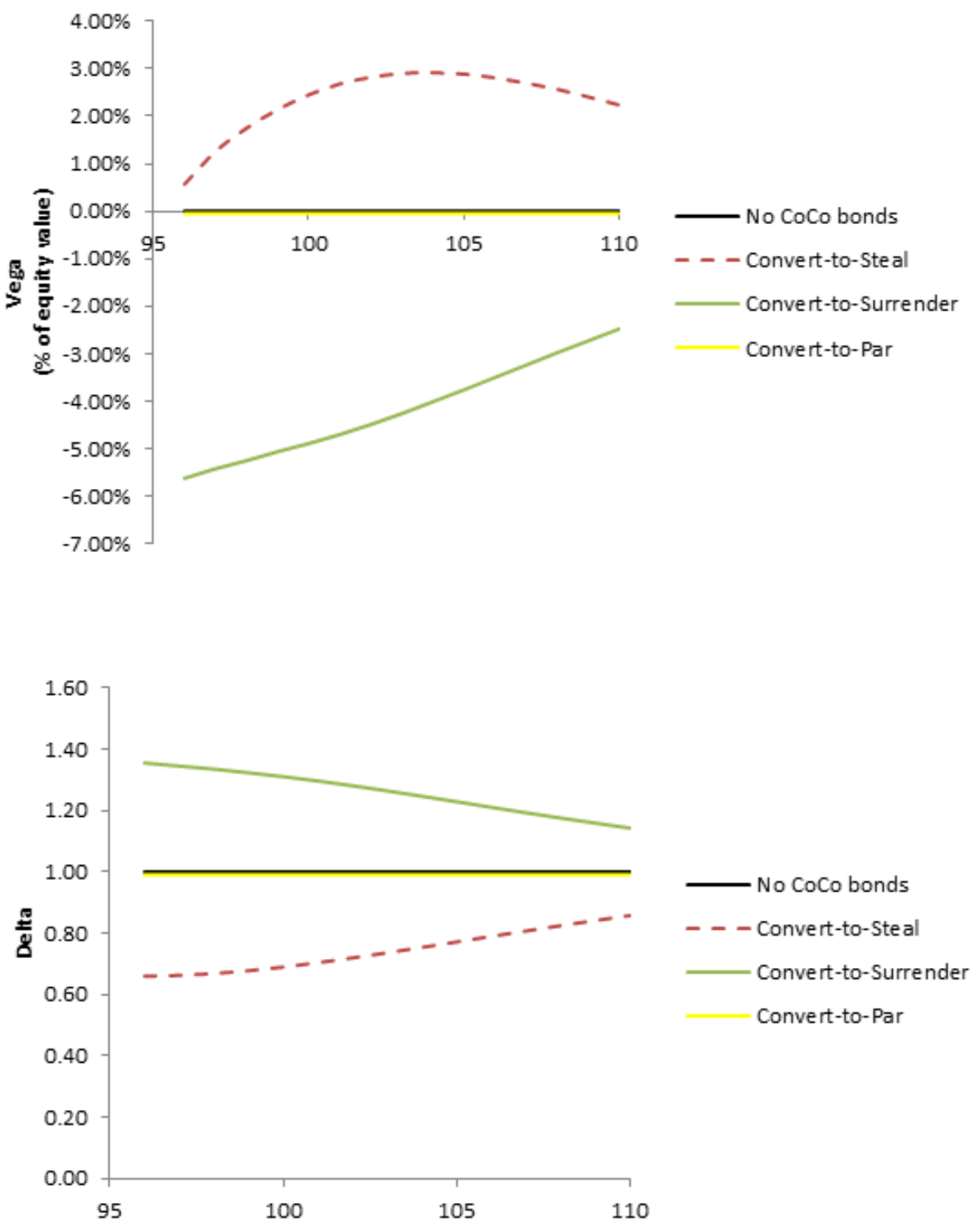


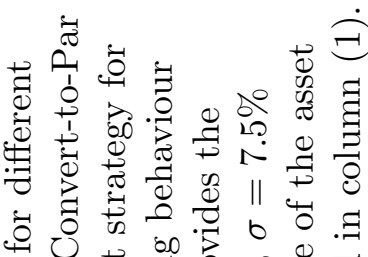

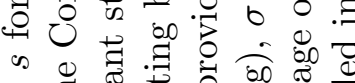

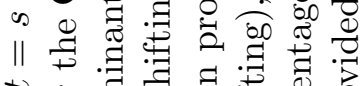

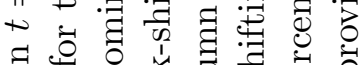
$\exists 4$ क्ष

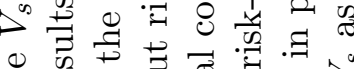
$引 \begin{aligned} & 0 \\ & 0\end{aligned}$

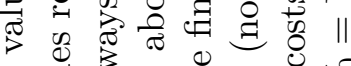

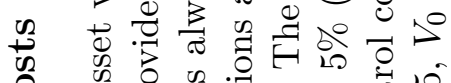
की

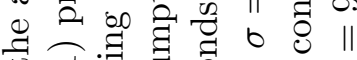

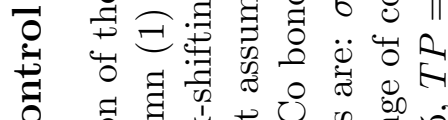

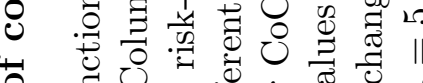

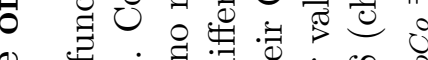
ठ Ш में

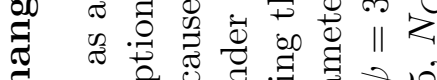

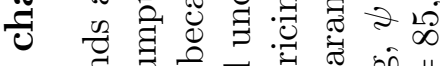
I 00 击

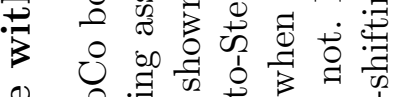

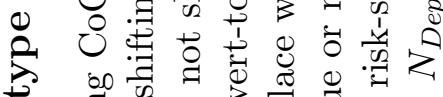

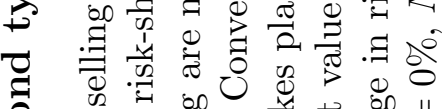

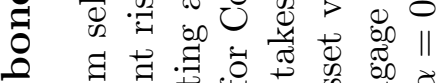

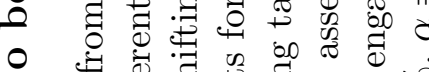
U U d ส

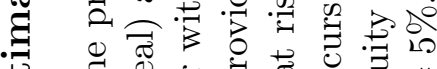

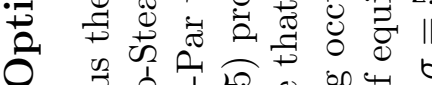

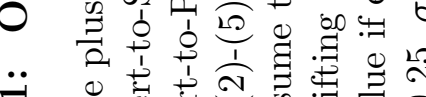

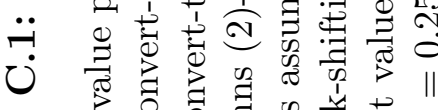
0.

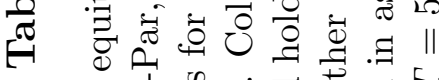

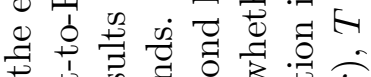

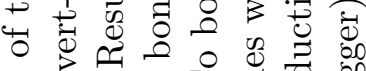
छ

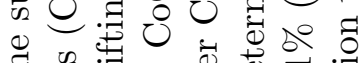

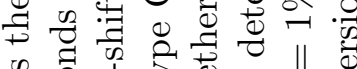

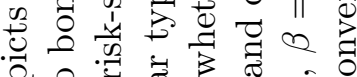
ठ유

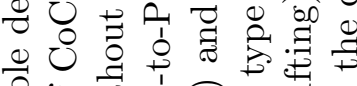

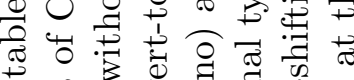

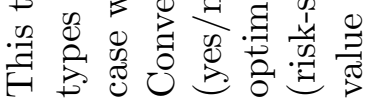

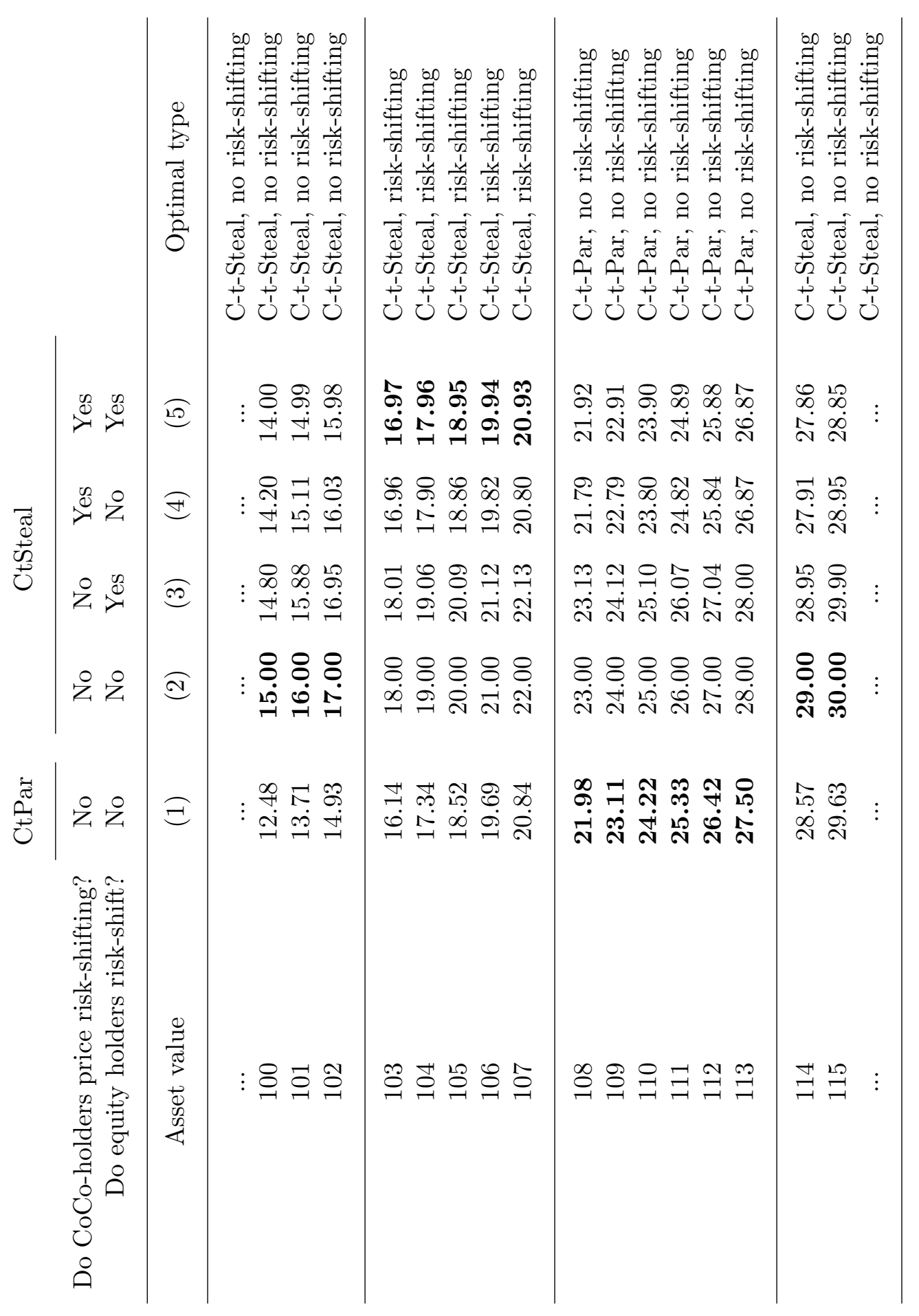

